\title{
The influences of mass loading and rapid dilution of secondary organic aerosol on particle volatility
}

\author{
K. R. Kolesar ${ }^{1}$, C. Chen ${ }^{1, a}$, D. Johnson ${ }^{1, b}$, and C. D. Cappa ${ }^{1}$ \\ ${ }^{1}$ Department of Civil and Environmental Engineering, University of California, Davis, One Shields Avenue, Davis, \\ California 95616, USA \\ ${ }^{a}$ now at: Sustainable Energy Initiative, Santa Clara University, 500 El Camino Real, Santa Clara, California 95053, USA \\ ${ }^{b}$ now at: Advanced Light Source, Lawrence Berkeley National Laboratory, 1 Cyclotron Rd, Berkeley, California 94720, USA \\ Correspondence to: C. D. Cappa (cdcappa@ucdavis.edu)
}

Received: 9 March 2015 - Published in Atmos. Chem. Phys. Discuss.: 2 April 2015

Revised: 23 July 2015 - Accepted: 4 August 2015 - Published: 21 August 2015

\begin{abstract}
The thermally induced evaporation of secondary organic aerosol (SOA) has been characterized for SOA formed from the dark ozonolysis of $\alpha$-pinene at initial mass concentrations ranging from 1 to $800 \mu \mathrm{g} \mathrm{m}^{-3}$. Temperaturedependent particle size distributions were measured using a thermodenuder and the resulting mass thermograms were compared between the SOA formed at the various SOA mass concentrations. Negligible differences were observed between the mass thermograms for SOA concentrations $<300 \mu \mathrm{g} \mathrm{m}^{-3}$. At higher SOA concentrations, the observed mass thermograms indicated the SOA was actually slightly less volatile than the SOA at lower concentrations; this is likely an artifact due to either saturation of the gas phase or to recondensation during cooling. The thermograms observed when the SOA was formed at high concentrations $\left(>380 \mu \mathrm{g} \mathrm{m}^{-3}\right.$ ) and then rapidly isothermally diluted to low concentrations $\left(1-20 \mu \mathrm{g} \mathrm{m}^{-3}\right)$ were identical to those for the SOA that was initially formed at low concentrations. The experimental results were compared to a kinetic model that simulates particle evaporation upon heating in a thermodenuder for a given input volatility distribution and particle composition. Three cases were considered: (1) the SOA was composed of semi-volatile monomer species with a volatility distribution based on that derived previously from consideration of SOA growth experiments; (2) the initial SOA was composed almost entirely of non-volatile dimers that decompose upon heating into their semi-volatile monomer units, which can then evaporate; and (3) where a volatility distribution was derived by fitting the model to the observed mass thermograms. It was found that good agreement
\end{abstract}

is obtained between model predictions and the observations when the particle composition is dominated by either compounds of low volatility or by dimers. These same models were used to simulate isothermal evaporation of the SOA and were found to be broadly consistent with literature observations that indicate that SOA evaporation occurs with multiple timescales. The use of the semi-volatile monomer volatility distribution fails to reproduce the observed evaporation. The presence of dimers and larger oligomers in secondary organic aerosol formed from products of the reaction of $\alpha$-pinene and $\mathrm{O}_{3}$ has been well established in laboratory studies. However, the timescale and relative importance of the formation of oligomers or low-volatility compounds in the growth and evaporation of SOA has been debated. This study provides further support that low-volatility compounds and oligomers are formed in $\alpha$-pinene $+\mathrm{O}_{3}$ in high abundances and suggests that their formation occurs rapidly upon particle formation.

\section{Introduction}

Atmospheric aerosol particles have an important impact on human health (Chen et al., 2013) and climate (IPCC, 2014). Organic aerosol (OA) is a significant portion of atmospheric particulate mass, often contributing $20-90 \%$ of the fine particle mass worldwide (Saxena and Hildemann, 1996; Andreae and Crutzen, 1997), a major portion of which is secondary organic aerosol (SOA) (Zhang et al., 2005). One pathway through which SOA is formed is when products from the 
gas-phase oxidation of volatile organic compounds (VOCs) condense onto pre-existing particles or nucleate to form new particles. VOCs are broadly classified as being either biogenic (BVOCs) or anthropogenic (AVOCs). The source of SOA varies with geographical location, with larger contributions of anthropogenic SOA in and around urban areas (Weber et al., 2007) and larger contributions of biogenic SOA in rural areas (Han et al., 2014).

An important source of biogenic SOA is the reaction of unsaturated gas-phase VOCs with $\mathrm{O}_{3}$. The most globally abundant BVOC compounds are isoprene $\left(\mathrm{C}_{5} \mathrm{H}_{8}\right)$ and monoterpenes $\left(\mathrm{C}_{10} \mathrm{H}_{16}\right)$ (Kesselmeier and Staudt, 1999). Around $90 \mathrm{TgC}^{-1}$ of monoterpenes are emitted from vegetation sources worldwide (Hallquist et al., 2009), of which $\alpha$ pinene constitutes nearly half (Guenther et al., 1995; Seinfeld and Pankow, 2003). During the formation of SOA from the ozonolysis of $\alpha$-pinene the aerosol composition and corresponding physical properties have been shown to change as a function of total organic aerosol mass loading $\left(\mathrm{C}_{\mathrm{OA}}\right)$. For example, Shilling et al. (2009) observe that both the O / C ratio and the effective density of $\alpha$-pinene $+\mathrm{O}_{3}$ SOA decrease as $C_{\mathrm{OA}}$ increases, most steeply below $\sim 30 \mu \mathrm{g} \mathrm{m}^{-3}$. Other studies have shown that the mass yield of a variety of SOA, including $\alpha$-pinene $+\mathrm{O}_{3} \mathrm{SOA}$, increases as $C_{\mathrm{OA}}$ increases (Henry et al., 2012; Odum et al., 1996; Pathak et al., 2007). Changes to aerosol composition as a function of $C_{\mathrm{OA}}$ can be explained by gas-particle partitioning in which the distribution of material between the gas and particle phases is related to the saturation vapor concentration, $C^{*}$, and the total OA concentration (Pankow, 1994; Odum et al., 1996) according to

$\frac{C_{i, \mathrm{p}}}{C_{i, \mathrm{tot}}}=\alpha_{i}\left(1+\frac{C_{i}^{*}}{C_{\mathrm{OA}}}\right)^{-1}$,

where $C_{i, \mathrm{p}}$ is the concentration of compound $i$ in the particle phase $\left(\mu \mathrm{g} \mathrm{m}^{-3}\right), C_{i, \text { tot }}$ is the total concentration of $i$ in both the gas and particle phase $\left(\mu \mathrm{g} \mathrm{m}^{-3}\right), C_{i}^{*}$ is the saturation vapor concentration $\left(\mu \mathrm{g} \mathrm{m}^{-3}\right)$, and $\alpha_{i}$ is the mass yield of compound $i$. When $C_{\mathrm{OA}}$ is equal to $C_{i}^{*}, 50 \%$ of compound $i$ exists in the particle phase. Compounds are generally considered semi-volatile when their $C_{i}^{*}$ are within 1-2 orders of magnitude of the concurrent $C_{\mathrm{OA}}$. According to gas-particle partitioning, as $C_{\mathrm{OA}}$ increases, the fraction of higher volatility compounds, which usually have a lower $\mathrm{O} / \mathrm{C}$ ratio, present in the condensed phase will increase. SOA growth experiments have historically been interpreted through the framework of absorptive gas-particle partitioning theory, where volatility distributions, i.e., distributions of $\alpha_{i}$ as a function of $C_{i}^{*}$ for some number of surrogate compounds, are derived by fitting the observed SOA formation (Odum et al., 1996; Donahue et al., 2006). Such analyses indicate that SOA is composed of a distribution of semi-volatile compounds with volatilities greater than $\sim 10^{-1} \mu \mathrm{g} \mathrm{m}^{-3}$. However, the volatility distributions deter- mined from fitting of growth experiments have been mostly unable to describe the reverse process, namely evaporation of SOA.

For example, quantitative estimates of the volatility of both ambient and laboratory OA after heating-induced evaporation indicate that there are often components of OA with significantly lower volatility than predicted by fitting of growth experiments (Cappa and Jimenez, 2010; Stanier et al., 2007). In addition, several experiments have observed slower than expected room-temperature evaporation of both ambient (Vaden et al., 2011) and laboratory-generated (Saleh et al., 2013; Grieshop et al., 2007; Wilson et al., 2015; Vaden et al., 2011) SOA during isothermal dilution. It has also been observed that the mass spectrum of $\alpha$-pinene $+\mathrm{O}_{3}$ SOA over the range 40-200 amu exhibited negligible changes during the heating-induced evaporation (Cappa and Wilson, 2011), even though absorptive gas-particle partitioning suggests an SOA composed of components having volatilities spanning several decades of $C^{*}$. Some other experiments have observed some changes to the observed particle composition (i.e., mass spectrum) upon heating (Hall and Johnston, 2012b; Kostenidou et al., 2009), but overall the changes tend to be small and inconsistent, with the particles being composed of individual compounds with a wide range of volatilities. Altogether these observations illustrate that there is a clear gap between the apparent volatility of SOA as characterized during evaporation experiments and the effective volatility of SOA derived from formation studies.

In this study, the volatility of $\alpha$-pinene $+\mathrm{O}_{3}$ SOA was characterized by heating-induced evaporation in a thermodenuder (TD) as a function of $C_{\mathrm{OA}}$ over the range 1 to $800 \mu \mathrm{g} \mathrm{m}^{-3}$. Based on previous SOA formation experiments, the SOA composition is expected to have changed as $C_{\mathrm{OA}}$ was increased from 1 to $>140 \mu \mathrm{g} \mathrm{m}^{-3}$ (Shilling et al., 2009). It follows that the SOA volatility should vary as a function of $C_{\mathrm{OA}}$ as well, with an expectation that SOA at higher $C_{\mathrm{OA}}$ should be more volatile than that at low $C_{\mathrm{OA}}$ and thus should exhibit different responses to heating. Additionally, mass thermograms of SOA that was initially formed at $C_{\mathrm{OA}}>380 \mu \mathrm{g} \mathrm{m}^{-3}$ and rapidly diluted to $C_{\mathrm{OA}}<30 \mu \mathrm{g} \mathrm{m}^{-3}$ were measured. The experimental results are interpreted using the kinetic model of aerosol evaporation in a TD by Cappa (2010) that has been extended from the original formulation that assumed direct evaporation of semi- or lowvolatility monomers to include dimer formation and decomposition. Good agreement between the experimental observations and the model predictions provides support for the large influence of oligomer decomposition on SOA evaporation. 


\section{Materials and methods}

\subsection{Secondary organic aerosol production}

SOA was formed in the absence of seed particles at various total $C_{\mathrm{OA}}$ from the formation and subsequent growth of nano-condensation nuclei that were formed from products of the ozonolysis of gas-phase $\alpha$-pinene, in excess (Fig. S1 in the Supplement). Variable amounts of $\alpha$-pinene were introduced into a stainless steel flowtube $(L=2 \mathrm{~m} ; \mathrm{ID}=2.3 \mathrm{~cm})$ by constantly injecting liquid $\alpha$-pinene $\left(0.12-0.7 \mu \mathrm{Lh}^{-1}\right)$ into a stream of purified house air at $0.015 \mathrm{~L} \mathrm{~min}^{-1}$. The $\mathrm{O}_{3}$ was generated by passing air through a cell containing a $22.9 \mathrm{~cm}$ long $\mathrm{Hg}$ pen-ray lamp (UVP, LLC) and then 0.70 $1.0 \mathrm{~L} \mathrm{~min}^{-1}$ of this flow was sub-sampled into the flowtube. The relative humidity of the air stream was $\sim 30 \%$ for all experiments. The concentrations of $\alpha$-pinene, $\mathrm{O}_{3}$ and other experiment-specific conditions are given in Table 1 . The residence time in the flow tube was typically about $1 \mathrm{~min}$, although slightly variable depending on the total volumetric flow rate (see Table 1). No $\mathrm{OH}$ scavenger was used. The $\mathrm{O}_{3}$ concentration was measured using an $\mathrm{O}_{3}$ monitor (model 450, API Inc.). Downstream of the flowtube, residual hydrocarbons and $\mathrm{O}_{3}$ were removed by passing the airstream through a Carulite 200 (Carus) catalyst and a charcoal denuder. The particles were assumed to have a density of $1.2 \mu \mathrm{g} \mathrm{m}^{-3}$. The particle mass concentrations were varied from 1 to $800 \mu \mathrm{g} \mathrm{m}^{-3}$, although they were kept stable for the duration of each experiment. Larger concentrations tended to correspond to particle size distributions that peaked at larger sizes.

In addition to SOA that was generated at variable $C_{\mathrm{OA}}$, seven experiments involved the dilution of SOA that was initially formed at high $C_{\mathrm{OA}}\left(\geq 380 \mu \mathrm{g} \mathrm{m}^{-3}\right)$ and diluted to low $C_{\mathrm{OA}}$. The dilution occurred downstream of the flowtube, charcoal denuder and ozone denuder. To achieve the desired dilution the aerosol-laden airstream was divided into two fractions: one was directed through a HEPA capsule filter with Versapor ${ }^{\circledR}$ membrane (Pall Corp.) to remove particles from the air stream and the other passed directly through $1 / 8$ in. copper tubing. The two air streams were recombined after the filter and passed directly to the TD. The fraction of the airstream directed through the HEPA filter, i.e., the level of dilution, was controlled by a needle valve attached to the outlet of the filter.

\subsection{Thermodenuder}

The TD used here is based on the design of Huffman et al. (2008) with the following key modifications: (1) the heated laminar flow reactor is $0.71 \mathrm{~m}$ long (as compared to $0.41 \mathrm{~m}$ ) and has a center line fully heated residence time $\left(\tau_{\text {res }}\right)$ of $26 \mathrm{~s}$ at a flow rate of $0.40 \mathrm{~L} \mathrm{~min}^{-1}$, (2) the distance between the actively heated volume and the charcoal denuder has been shortened and is now $4.8 \mathrm{~cm}$ (as compared to $\sim 14 \mathrm{~cm}$ ), and (3) there is only one heating region. The shorter distance between the end of the actively heated volume and the charcoal denuder helps to limit recondensation as the air cools prior to reaching the denuder section. The bypass (i.e., unheated) line had the same volume as the TD, and thus the same total residence time. Further information on the design and characterization of the TD is provided in the Supplement. The room-temperature flowrate through the TD was a constant $0.40 \mathrm{~L} \mathrm{~min}^{-1}$, independent of the total flowrate in the SOA formation flowtube. Measurements of the particle size distribution were made after the particles passed through either the bypass line (room temperature) or the TD. The TD temperature ranged from room temperature ( $298 \mathrm{~K})$ to $220^{\circ} \mathrm{C}(493 \mathrm{~K})$. No differences in the mass thermograms were found between experiments based on the order of temperature changes, e.g., whether temperature was increased or decreased.

\subsection{Measurements}

A scanning mobility particle sizer (SMPS; TSI Inc.), composed of a charge neutralizer, a differential mobility analyzer (DMA; model 3085) and a condensation particle counter (CPC; model 3772), was used to measure particle size distributions. The extent of aerosol evaporation was characterized by comparing the particle size distribution for particles that passed through the bypass line to that for the particles after passing through the TD. The size distributions were characterized by their volume-weighted median diameter, $d_{\mathrm{p}, \mathrm{V}}$. The particle volume fraction remaining (VFR) after passing through the TD is then

$\mathrm{VFR}=\frac{\frac{\pi}{6} \times d_{\mathrm{p}, \mathrm{V}, \mathrm{TD}}^{3}}{\frac{\pi}{6} \times d_{\mathrm{p}, \mathrm{V}, \text { bypass }}^{3}}$,

where $d_{\mathrm{p}, \mathrm{V}, \mathrm{TD}}$ and $d_{\mathrm{p}, \mathrm{V}, \text { bypass }}$ refer to the particles that passed through the TD or the bypass, respectively. Under an assumption of constant particle density, the VFR is equivalent to the particle mass fraction remaining (MFR), and plots of VFR versus temperature are commonly referred to as mass thermograms. The bypass distribution was measured at least every two temperature changes ( $\sim$ every $20 \mathrm{~min}$ ) to account for any changes in the reference particle distribution; in general, the reference distributions were very stable.

To facilitate quantitative comparison between experiments at different $C_{\mathrm{OA}}$, each mass thermogram was fit to the sigmoidal type equation from Emanuelsson et al. (2013):

$\operatorname{VFR}(T)=\mathrm{VFR}_{\max }+\left(\frac{\mathrm{VFR}_{\min }-\mathrm{VFR}_{\text {max }}}{1+\left(\frac{T_{50}}{T}\right)^{S_{\mathrm{VFR}}}}\right)$,

where $\mathrm{VFR}_{\min }$ is the VFR at the low-temperature limit, $\mathrm{VFR}_{\max }$ is the VFR at the high-temperature limit (typically zero), $S_{\mathrm{VFR}}$ is the slope factor that characterizes the steepness 
Table 1. Experimental conditions for $\alpha$-pinene $+\mathrm{O}_{3}$ SOA generation for the various experiments.

\begin{tabular}{lrrrrrr}
\hline $\begin{array}{l}\text { Experiment } \\
\text { date }\end{array}$ & $\begin{array}{r}\text { Flowrate } \\
\left(\mathrm{L} \mathrm{min}^{-1}\right)\end{array}$ & $\begin{array}{r}\text { Initial } C_{\mathrm{OA}} \\
\left(\mu \mathrm{g} \mathrm{m}^{-3}\right)\end{array}$ & $\begin{array}{r}C_{\mathrm{OA}} \text { after dilution } \\
\left(\mu \mathrm{g} \mathrm{m}^{-3}\right)\end{array}$ & $\begin{array}{r}\alpha \text {-pinene } \\
\left(\mu \mathrm{L} \mathrm{h}^{-1}\right)\end{array}$ & $\begin{array}{r}\text { Ozone } \\
(\mathrm{ppm})\end{array}$ & $\begin{array}{r}d_{\mathrm{p}, \mathrm{V}, \text { bypass }} \\
(\mathrm{nm})\end{array}$ \\
\hline 05 Sep 2012 & 0.79 & 1 & $\mathrm{n} / \mathrm{a}$ & 0.12 & 4.9 & 37 \\
29 Aug 2012 & 0.8 & 9 & $\mathrm{n} / \mathrm{a}$ & 0.12 & 7.8 & 39 \\
19 Oct 2012 & 0.8 & 30 & $\mathrm{n} / \mathrm{a}$ & 0.6 & 8.8 & 52 \\
11 Apr 2014 & 0.82 & 90 & $\mathrm{n} / \mathrm{a}$ & 0.15 & 38.7 & 48 \\
07 Sep 2012 & 0.81 & 150 & $\mathrm{n} / \mathrm{a}$ & 0.3 & 6.8 & 61 \\
13 Sep 2012 & 0.8 & 180 & $\mathrm{n} / \mathrm{a}$ & 0.2 & $\mathrm{~b}$ & 57 \\
09 Apr 2014 & 0.82 & 200 & $\mathrm{n} / \mathrm{a}$ & $0.23 \mathrm{a}$ & 63 & 57 \\
12 Sep 2012 & 0.8 & 400 & $\mathrm{n} / \mathrm{a}$ & 0.5 & $\mathrm{~b}$ & 73 \\
16 Oct 2012 & 0.8 & 450 & $\mathrm{n} / \mathrm{a}$ & 0.6 & 8.8 & 83 \\
17 Oct 2012 & 0.8 & 500 & $\mathrm{n} / \mathrm{a}$ & 0.6 & 8.8 & 88 \\
11 Sep 2012 & 0.8 & 600 & $\mathrm{n} / \mathrm{a}$ & 0.38 & 23.4 & 76 \\
18 Oct 2012 & 0.83 & 800 & $\mathrm{n} / \mathrm{a}$ & 0.6 & 8.8 & 97 \\
12 Oct 2012 & 0.83 & 380 & 5 & 0.6 & 8.8 & 73 \\
09 Oct 2012 & 1.02 & 380 & 6 & 0.7 & 9.8 & 71 \\
11 Oct 2012 & 0.79 & 430 & 7 & 0.5 & 9.7 & 73 \\
10 Oct 2012 & 0.8 & 450 & 10 & 0.5 & 8.8 & 77 \\
31 Aug 2012 & 0.8 & 600 & 14 & 0.5 & 29.3 & 76 \\
24 Sep 2012 & 0.76 & 650 & 23 & 0.5 & 9.7 & 90 \\
04 Oct 2012 & 1.04 & 450 & 23 & 0.5 & 8.8 & 68 \\
\hline
\end{tabular}

a The flowrate of $\mathrm{N}_{2}$ over the $\alpha$-pinene syringe was $0.015 \mathrm{~L} \mathrm{~min}^{-1}$ for all experiments except this one, for which it was $0.074 \mathrm{~L} \mathrm{~min}^{-1}$. ${ }^{\mathrm{b}}$ Unknown.

of the VFR curve and $T_{50}$ is the temperature at which VFR $=0.50$. If there is no evaporation in the TD at room temperature due to the removal of gas-phase compounds (vapor stripping) in the denuder section, then the VFR at room temperature $(298 \mathrm{~K})$ should be, by definition, unity. Best-fit VFR $\min$ values greater than unity may, however, be obtained because Eq. (3) is an empirical expression and thus is not expected to provide a perfect match with the observations, although it can nonetheless facilitate comparison between different experiments. Here, to provide for more consistent fitting, and since no evaporation was observed at room temperature, the fit curves were forced to go through unity at room temperature.

\subsection{Kinetic model of evaporation}

\subsubsection{Thermodenuder model}

The kinetic model of evaporation used here is a modified version of the model developed by Cappa (2010) to simulate evaporation in a thermodenuder. The original model simulated gas-particle mass transfer (evaporation and condensation) for a monomodal multi-component aerosol as particles pass through and are heated and cooled in the TD along with loss of vapors to the charcoal denuder. Absorptive partitioning is implicitly assumed. Compounds evaporate according to their respective saturation vapor concentrations, and it is assumed that the gas-particle system is at equilibrium before entering the TD. The temperature dependence of
$C^{*}$ is accounted for using the Clausius-Clapeyron equation. Here, it is assumed that the enthalpy of vaporization, $\Delta H_{\text {vap }}$, is related to $C^{*}$ according to the relationship of Epstein et al. (2010), where $\Delta H_{\text {vap }}\left(\mathrm{kJ} \mathrm{mol}^{-1}\right)=131-11 \times \log C^{*}$. The temperature profile through the TD is empirically specified (see Supplement). The key input to the model is the distribution of mass (gas + particle) with respect to $C^{*}$, referred to as a volatility distribution; different distributions will yield different mass thermograms (Cappa and Jimenez, 2010). It is commonplace to assume a distribution where the $C^{*}$ values differ by an order of magnitude at a specified reference temperature, e.g., $\log C^{*}(298 \mathrm{~K})=(-3,-2,-1,0,1,2,3)$, and this approach is adopted here. The calculated mass transfer rates can be adjusted to account for mass transfer limitations, as characterized by the evaporation coefficient, $\gamma_{\mathrm{e}}$, which characterizes deviations from the theoretical maximum evaporation rate; $\gamma_{\mathrm{e}}$ is an adjustable parameter as it is not known a priori. The default value used is $\gamma_{\mathrm{e}}=1$. The model output for a given set of $\Delta H_{\text {vap }}$ and $C^{*}$ is dependent on $\gamma_{\mathrm{e}}$. At smaller $\gamma_{\mathrm{e}}$ the slope of the mass thermogram is less steep, the $T_{50}$ increases, and for SOA with semi-volatile components an increasing amount of mass remains after TD processing at room temperature (Cappa and Wilson, 2011). The model can be run with pre-specified volatility distributions or can be used to determine empirical volatility distributions from fitting to observations (Cappa and Jimenez, 2010).

The base TD model has been modified to include the influence of dimers and dimer decomposition on the simulated evaporation, and shares some similarities with Trump and 
Donahue (2014). The dimer model is implemented as follows. The initial equilibrium gas-particle mass distribution is based on a semi-volatile monomer volatility distribution (i.e., that determined from previous growth experiments). The balance between monomers and dimers at equilibrium is then determined from the monomer-dimer equilibrium constant, $K_{\text {eqm }}\left(\mathrm{cm}^{3}\right.$ molecules $\left.{ }^{-1}\right)$, which is equal to the ratio of the forward $\left(k_{\mathrm{f}}, \mathrm{cm}^{3}\right.$ molecule $\left.{ }^{-1} \mathrm{~s}^{-1}\right)$ and reverse $\left(k_{\mathrm{r}}, \mathrm{s}^{-1}\right)$ rate coefficients associated with formation from monomers and dimer decomposition, i.e., $K_{\text {eqm }}=k_{\mathrm{f}} / k_{\mathrm{r}}$. Note that the volume units on $K_{\text {eqm }}$ and $k_{\mathrm{f}}$ correspond to condensed-phase volume. If $K_{\text {eqm }}$ is large then all condensed-phase species would be in dimer form and, at equilibrium, all gas-phase material would be drawn into the condensed phase, assuming that the monomers are miscible with the dimers. Here, this situation is avoided through the following simplification to determine the initial particle state at the TD inlet. First, the gas-particle (monomer only) equilibrium distribution is calculated given the specified volatility distribution and $C_{\mathrm{OA}}$. Then the monomer-dimer equilibrium in the condensed phase only is calculated based on the current condensed-phase monomer concentrations. The gas-phase concentrations are then set to zero to avoid large amounts of condensing material at the next time step. Since a charcoal denuder is placed immediately after the flowtube, this simplification is physically reasonable as we have previously found that vapor stripping in charcoal denuders is efficient (Cappa and Wilson, 2011). The resulting monomer-dimer concentrations in the condensed phase are used as the initial state. The above simplification for the initial particle state most likely does not provide a true representation of the actual particle composition, just as the assumption regarding only homodimers (discussed below) is a simplification. However, as we ultimately find that the simulation results are much more sensitive to the initial distribution of particulate mass with respect to monomers and dimers than to the specific distribution of monomers with respect to their volatility, these simplifications will influence the details but not the general conclusions arrived at here.

It is assumed that the dimers are non-volatile over the entire temperature range considered, and thus do not directly evaporate. In addition, only homodimers - that is, dimers formed from monomers in the same volatility bin - are assumed to form. This is a simplification compared to allowing for all possible cross-reactions and allows for the dimer source monomers to be kept track of in a more straightforward manner. As the temperature increases within the TD, the dimers decompose into their semi-volatile parent monomers, which can then evaporate according to their saturation vapor concentration. It was assumed that there were no mass transport limitations within the particle phase for all evaporating species, i.e., that the surface composition was always equivalent to the bulk composition. As the semi-volatile monomers evaporate the equilibrium state is perturbed and the dimers decompose in response, ac- cording to the temperature-dependent $K_{\text {eqm }}$, to re-establish dimer/monomer equilibrium. Depending on the timescale of dimer formation and decomposition, the dimers and monomers may not be in equilibrium at every step of the model, yet they are constantly forming and decomposing to move towards equilibrium. Experimental observations by Hall and Johnston (2012b) have shown that dimers in SOA do decompose upon heating. The rate at which dimers decompose is governed by changes to $k_{\mathrm{r}}$ and $k_{\mathrm{f}}$, as a function of temperature. Assuming they exhibit Arrhenius-type temperature dependence, the temperature sensitivity of $K_{\text {eqm }}$ can be characterized by the difference in the activation energies of the reverse and forward reactions, $\Delta E_{\mathrm{a}}=E_{\mathrm{a}, \mathrm{r}}-E_{\mathrm{a}, \mathrm{f}}$, and where the temperature dependence of $k_{\mathrm{r}}$ and $k_{\mathrm{f}}$ has the form

$k_{\mathrm{r}}(T)=k_{\mathrm{r}}(298 \mathrm{~K}) \times e^{\left(-\frac{E_{\mathrm{a}, \mathrm{r}}}{R T}+\frac{E_{\mathrm{a}, \mathrm{r}}}{R \times 298 \mathrm{~K}}\right)}=A_{\mathrm{r}} \times e^{-\frac{E_{\mathrm{a}, \mathrm{r}}}{R T}}$,

where $R$ is the universal gas constant $\left(8.314 \mathrm{~J} \mathrm{~mol}^{-1} \mathrm{~K}\right)$ and $T$ is the temperature (K) and where

$A_{\mathrm{r}}=k_{\mathrm{r}}(298 \mathrm{~K}) \times e^{-\frac{E_{\mathrm{a}}}{R \times 298}}$.

Note that the Arrhenius pre-factor, $A_{\mathrm{r}}$, depends on $E_{\mathrm{a}, \mathrm{r}}$. Consequently,

$$
\begin{aligned}
& K_{\text {eqm }}(T)=\frac{k_{\mathrm{r}}(298 \mathrm{~K})}{k_{\mathrm{f}}(298 \mathrm{~K})} \times e^{-\frac{\Delta E_{\mathrm{a}}}{R \times 298 \mathrm{~K}}} \times e^{-\frac{\Delta E_{\mathrm{a}}}{R T}} \\
& =\frac{A_{\mathrm{r}}}{A_{\mathrm{f}}} \times e^{\frac{\Delta E_{\mathrm{a}}}{R T}}
\end{aligned}
$$

and $\Delta E_{\mathrm{a}}$ is as defined above. It should be noted that this formulation differs somewhat from that of Trump and Donahue (2014) in that they assumed that $A$ and $E_{\mathrm{a}}$ were independent parameters and further did not account for the temperature dependence of $k_{\mathrm{f}}$, which we account for here in the relationship between $k_{\mathrm{r}}, k_{\mathrm{f}}$ and $\Delta E_{\mathrm{a}}$. The key model inputs are then $K_{\text {eqm }}(298 \mathrm{~K}), k_{\mathrm{r}}(298 \mathrm{~K})$ and $\Delta E_{\mathrm{a}}$. Although $K_{\text {eqm }}$ governs the equilibrium distribution, $k_{\mathrm{f}}$ and $k_{\mathrm{r}}$ will control the timescales associated with dimer formation and the approach to equilibrium in the particles.

\subsubsection{Isothermal evaporation model}

The kinetic thermodenuder model of evaporation was adapted to allow for simulation of particle evaporation at room temperature following from isothermal dilution for any initial input of particle composition including semi-volatile monomers, very low volatility compounds and a mixture of semi-volatile monomers and non-volatile dimers. The extent of dilution is user-selectable as a dilution factor (DF), which simulates SOA and the associated vapors being passed through a DMA and injected into a chamber. The organic vapors are assumed to be removed from the system (i.e., lost to the chamber walls) at a rate characterized by a user-selectable first-order loss rate, $k_{\text {loss }}\left(\mathrm{s}^{-1}\right)$. Vapor loss serves to mimic the conditions in some isothermal evaporation experiments 


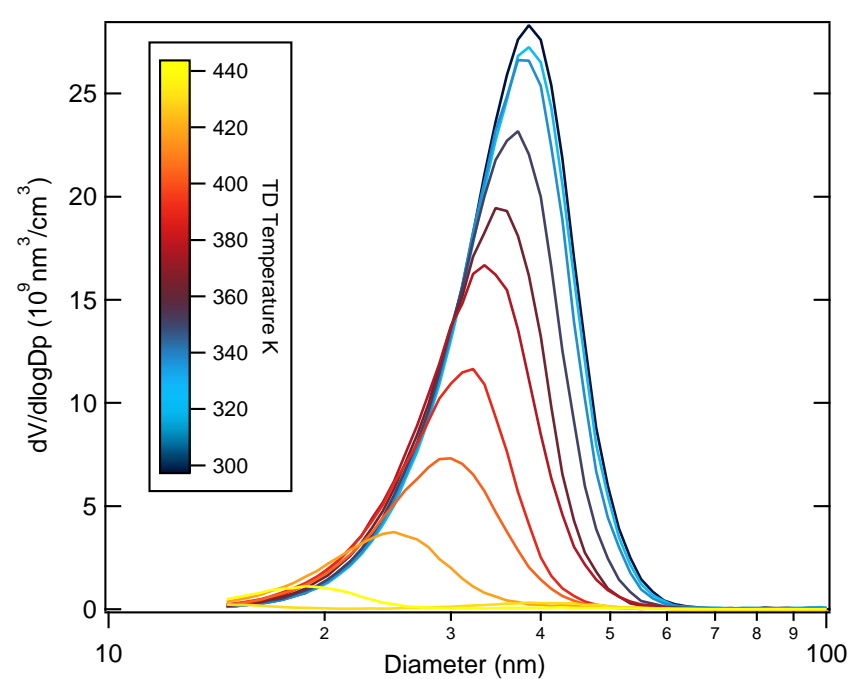

Figure 1. An example of the particle volume-weighted size distributions observed as a function of TD temperature from one experiment. The temperatures range from room temperature $(296 \mathrm{~K}$, light blue) to $453 \mathrm{~K}$ (purple). This experiment had a bypass $C_{\mathrm{OA}}=$ $9 \mu \mathrm{g} \mathrm{m}^{-3}$ and $d_{\mathrm{p}, \mathrm{V}, \text { bypass }}=39 \mathrm{~nm}$.

where the diluted SOA particles are held in a chamber containing activated carbon (Vaden et al., 2011). The timescales associated with isothermal evaporation are much longer than for the TD experiments and simulations, and the isothermal evaporation model can be run for many hours of model time. When the monomer-dimer equilibrium is used to establish the initial particle composition, the relationships between $K_{\text {eqm }}, k_{\mathrm{r}}, k_{\mathrm{f}}$ and $\Delta E_{\mathrm{a}}$ are the same as in the TD evaporation model.

\section{Results and discussion}

\subsection{Observations}

Evaporation and shrinking of the $\alpha$-pinene $+\mathrm{O}_{3}$ SOA particles occurred upon heating in the TD. Example size distributions as a function of temperature for an initial $C_{\mathrm{OA}}=9 \mu \mathrm{g} \mathrm{m}^{-3}$ are shown in Fig. 1. The mass thermograms for each individual experiment are shown in Fig. 2. The experimental results have been grouped according to the bypass $C_{\mathrm{OA}}$ for each experiment, with groupings of (i) high, $\mathrm{C}_{\mathrm{OA}}>$ $300 \mu \mathrm{g} \mathrm{m}^{-3}$; (ii) medium, $90 \leq \mathrm{C}_{\mathrm{OA}}<300 \mu \mathrm{g} \mathrm{m}^{-3}$; and low, $\mathrm{C}_{\mathrm{OA}} \leq 30 \mu \mathrm{g} \mathrm{m}^{-3}$. The demarcations were chosen based on the results from Shilling et al. (2009), who observed that particle composition varied with $C_{\mathrm{OA}}$. Results from experiments where SOA was formed at a high $C_{\mathrm{OA}}\left(>300 \mu \mathrm{g} \mathrm{m}^{-3}\right)$ and then rapidly isothermally diluted to a lower concentration $\left(<30 \mu \mathrm{g} \mathrm{m}^{-3}\right)$ are also reported in Fig. 2. Each experiment was individually fit according to Eq. (3), and the best-fit parameters are given in Table $S 1$ in the Supplement. The average $T_{50}$ and $S_{\mathrm{VFR}}$ for each $C_{\mathrm{OA}}$ grouping are given in Table 2.
Within each grouping the mass thermograms are all very similar, especially for the low and medium cases. No evaporation is observed at room temperature from vapor stripping in the denuder section for any case. The maximum variability is observed within the high- $C_{\mathrm{OA}}$ grouping, although even here the variability is not particularly large, with the average and sample standard deviation $S_{\mathrm{VFR}}=16.4 \pm 1.5$ and in $T_{50}=359 \pm 7 \mathrm{~K}$. The $S_{\mathrm{VFR}}$ 's for all groupings are statistically indistinguishable, as are the $T_{50}$ values for the low and medium groupings. However, the $T_{50}$ for the high- $C_{\mathrm{OA}}$ grouping is significantly larger at the $p<0.05$ level ( $p=$ 0.006 and $p=0.025$ as compared to the low- and medium$C_{\mathrm{OA}}$ groupings, respectively, for a two-tailed test). Visual inspection of Fig. 2a indicates that one experiment, with $C_{\mathrm{OA}}=600 \mu \mathrm{g} \mathrm{m}^{-3}$, has a notably larger $T_{50}$. If this experiment is excluded, the $T_{50}=357 \pm 5 \mathrm{~K}$, which is still statistically larger than the low $C_{\mathrm{OA}} T_{50}$ at the $p<0.05$ level ( $p=0.008$ for the two-tailed test) but is only now statistically larger than the medium $C_{\mathrm{OA}} T_{50}$ at the $p<0.10$ level ( $p=0.079$ for the two-tailed test). This difference could be due to small amounts of recondensation or to saturation of the gas phase, both of which become a greater concern at high $C_{\mathrm{OA}}$ (Cappa, 2010; Saleh et al., 2011; Cappa and Jimenez, 2010; Fuentes and McFiggans, 2012; Riipinen et al., 2010), although there is no specific dependence of $T_{50}$ on $C_{\mathrm{OA}}$ within the high- $C_{\mathrm{OA}}$ group. Regardless, it is apparent that the effective volatility of the SOA at high $C_{\mathrm{OA}}$ is not higher than at low $C_{\mathrm{OA}}$ and that, despite the slight differences, the response to heating of SOA particles formed from products of the ozonolysis of $\alpha$-pinene is, to a very large extent, independent of the $C_{\mathrm{OA}}$ at the point of formation. This then suggests that, from a volatility perspective, the distribution of compounds in the particle is independent of $C_{\mathrm{OA}}$, which stands in contrast to expectations based on the growthderived volatility distribution.

The mass thermogram of SOA originally formed at high $C_{\mathrm{OA}}$ and isothermally diluted to low $C_{\mathrm{OA}}$ was also measured (Fig. 2d). Since the evaporation of SOA induced by isothermal dilution occurs very slowly, on the order of many minutes to hours (Grieshop et al., 2007; Saleh et al., 2013), the composition of the diluted SOA is not expected to change substantially from the initial state of formation at high $C_{\mathrm{OA}}$ before the particles enter the TD. The $T_{50}$ of the SOA formed at high $C_{\mathrm{OA}}$ is larger than for the diluted SOA, and significantly different at the $p<0.05$ level ( $p=0.003$ for a twotailed test), while the average $S_{\mathrm{VFR}}$ 's of the diluted and the high- $C_{\mathrm{OA}}$ grouping mass thermograms are statistically indistinguishable at the $p<0.05$ level ( $p=0.443$ for the twotailed test). This strongly suggests that the difference in $T_{50}$ of the high- $C_{\mathrm{OA}}$ grouping results from recondensation or saturation of the gas phase, although the possibility that there is some real difference in the effective volatility of particles after rapid isothermal dilution cannot be excluded. The average diluted SOA mass thermogram is also almost identical to the average low- $C_{\mathrm{OA}}$ mass thermogram, indicating that the 

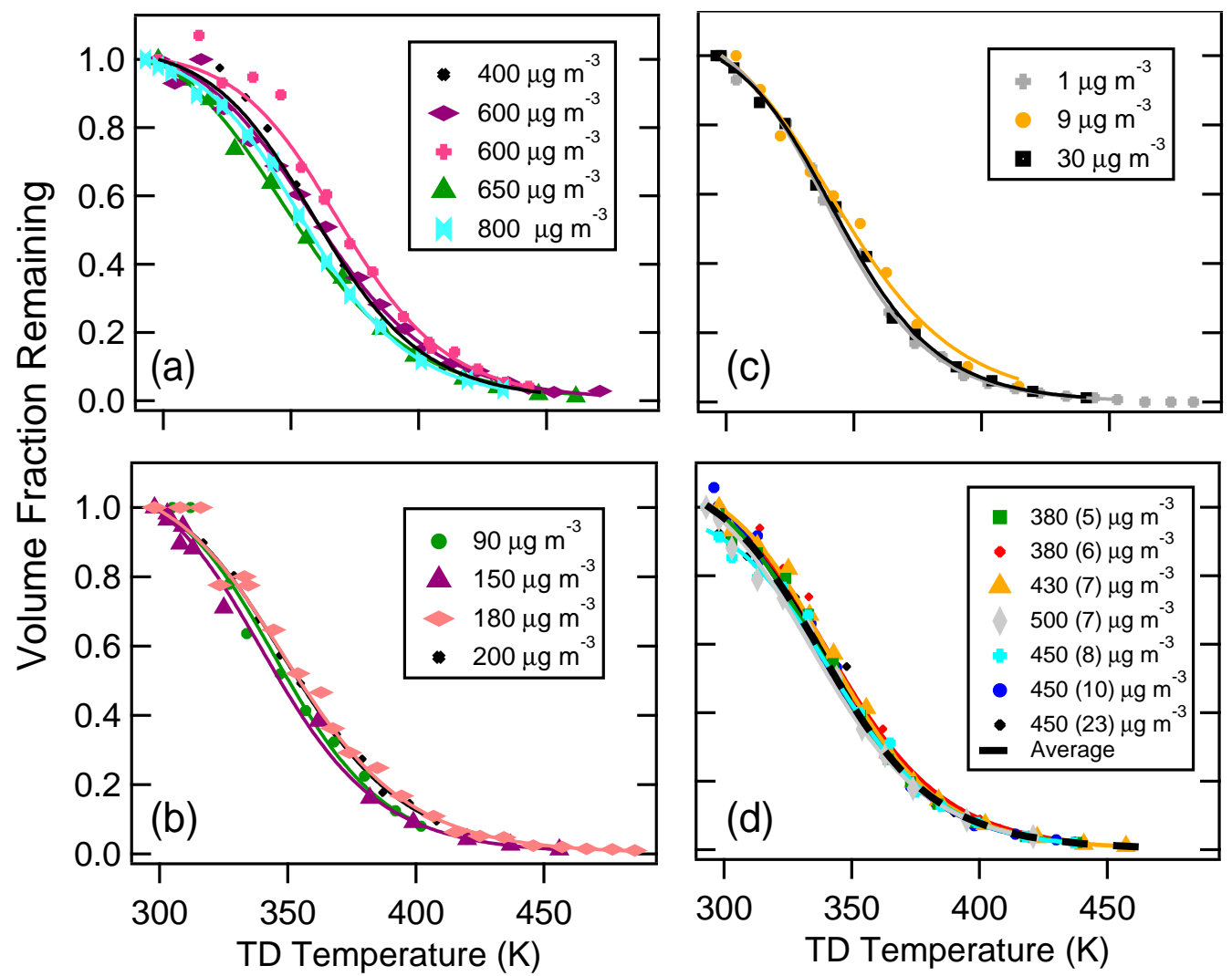

Figure 2. Mass thermograms measured for each of the experiments (symbols). Results are grouped according to the bypass mass loading as (a) high $\left(C_{\mathrm{OA}}>300 \mu \mathrm{g} \mathrm{m}^{-3}\right)$, (b) medium $\left(90 \leq C_{\mathrm{OA}}<300 \mu \mathrm{g} \mathrm{m}^{-3}\right)$, and (c) low loading $\left(C_{\mathrm{OA}} \leq 30 \mu \mathrm{g} \mathrm{m}{ }^{-3}\right)$. Results from isothermal dilution experiments are shown in (d), where the initial number is the $C_{\mathrm{OA}}$ before dilution and the number in parentheses is that after dilution. Traces represent the fit of Eq. (2) to each experiment.

Table 2. The average fit parameters for each $C_{\mathrm{OA}}$ grouping of mass thermograms.

\begin{tabular}{lccr}
\hline Mass loading range $\left(\mu \mathrm{g} \mathrm{m}^{-3}\right)$ & $S_{\mathrm{VFR}} \pm \sigma_{\mathrm{e}}^{*}$ & $T_{50} \pm \sigma_{\mathrm{e}}(\mathrm{K})$ & \# of samples \\
\hline Diluted $(<23)$ & $-15.9 \pm 1.6$ & $346 \pm 7$ & 7 \\
Low $(\leq 30)$ & $-16.6 \pm 1.9$ & $345 \pm 5$ & 3 \\
Medium $\left(90<C_{\mathrm{OA}}<200\right)$ & $-15.7 \pm 1.6$ & $347 \pm 6$ & 4 \\
High $(>300)$ & $-16.4 \pm 1.5$ & $359 \pm 7$ & 5 \\
\hline
\end{tabular}

* $\sigma_{\mathrm{e}}$ is the greater of the propagation of error from the individual fits and the sample standard deviation.

volatility distributions of the compounds in the diluted and low- $C_{\mathrm{OA}}$ cases are the same. Overall, it is evident that the rapid dilution of SOA does not induce changes to molecular composition that significantly influence particle volatility.

\subsection{Evaporation modeling}

\subsubsection{Semi-volatile SOA model}

The observed similarity between the mass thermograms for the SOA formed at orders-of-magnitude-different $C_{\mathrm{OA}}$ is surprising given that some observations suggest that particle composition depends on $C_{\mathrm{OA}}$ (e.g., Shilling et al., 2009).
Since the application of absorptive partitioning theory to the interpretation of SOA growth experiments suggests that the particles are (i) composed of compounds with a large distribution of individual volatilities, typically with $C^{*}$ values $>10^{-1} \mu \mathrm{g} \mathrm{m}^{-3}$ and (ii) that the fraction of higher volatility compounds should increase with increasing $C_{\mathrm{OA}}$, the mass thermograms are expected to depend on $C_{\mathrm{OA}}$. Using a volatility distribution for $\alpha$-pinene $+\mathrm{O}_{3} \mathrm{SOA}$ derived from SOA formation experiments (Pathak et al., 2007), simulated mass thermograms have been calculated as a function of $C_{\mathrm{OA}}$ (for $\gamma_{\mathrm{e}}=1$ or 0.001 ) using the TD model, first assuming that the particles are composed only of monomers (Fig. 3). Results from this model will be referred to as semi-volatile monomer 


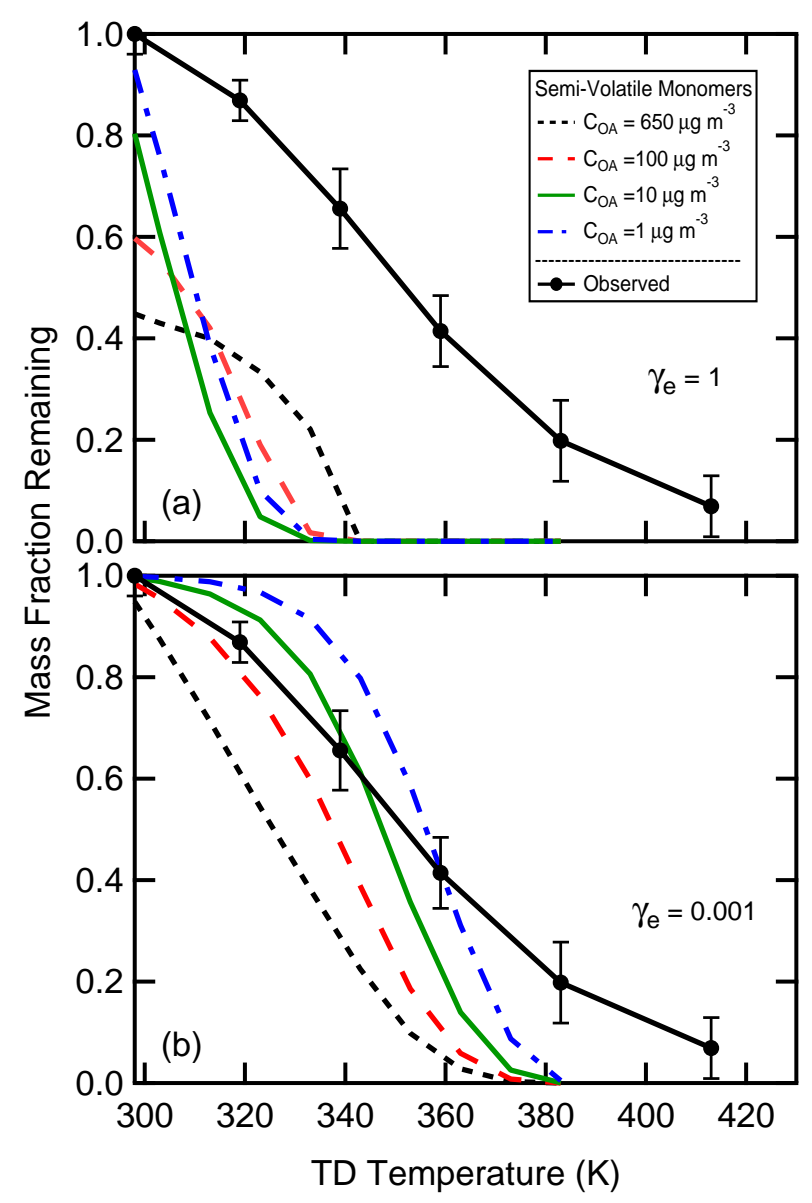

Figure 3. Model predictions for the mass thermograms of $\alpha$ pinene $+\mathrm{O}_{3}$ SOA using the semi-volatile monomer TD model where the initial model $C_{\mathrm{OA}}$ was $650 \mu \mathrm{g} \mathrm{m}^{-3}$ (black, short dash), $100 \mathrm{~g} \mathrm{~m} \mathrm{~m}^{-3}$ (red, long dash), $10 \mu \mathrm{g} \mathrm{m}^{-3}$ (green, solid) or $1 \mu \mathrm{g} \mathrm{m}^{-3}$ (blue, dot-dash) for evaporation coefficients, $\gamma_{\mathrm{e}}$, equal to (a) 1 and (b) 0.001 . Neither set of predictions agrees well with the observed mass thermogram for medium/low $C_{\mathrm{OA}}$ (black line with black $\bullet$ ).

results. Specifically, we use the seven-bin volatility distribution with $\log C^{*}=[-2,-1,0,1,2,3,4]$ and mass yields of $\alpha=[0.001,0.012,0.037,0.088,0.099,0.250,0.800]$. The theoretical mass thermograms, for $\gamma_{\mathrm{e}}=1$, indicate that a significant dependence of the mass thermograms on $C_{\mathrm{OA}}$ should have been observed (Fig. 3a). Further, they indicate that substantial evaporation of the SOA particles at high $C_{\mathrm{OA}}$ should have been observed at room temperature due to vapor stripping in the charcoal denuder section of the TD, which occurs to some extent for any species with $C^{*} \geq \sim 1 \mu \mathrm{g} \mathrm{m}^{-3}$ when $\gamma_{\mathrm{e}}$ $=1$. Neither of these phenomena were observed, demonstrating that there is a clear disconnect between typical volatility distributions derived from SOA growth experiments and SOA evaporation experiments, as has previously been noted (e.g., Cappa and Jimenez, 2010).

Some measurements of time-dependent evaporation profiles of SOA have been interpreted as suggesting that $\gamma_{\mathrm{e}}$ is significantly less than unity for $\alpha$-pinene $+\mathrm{O}_{3}$ SOA due to mass transfer limitations in the condensed phase (Grieshop et al., 2007; Saleh et al., 2013; Karnezi et al., 2014). Further, some TD-based SOA studies have used $\gamma_{\mathrm{e}}$ as a tunable parameter in data fitting for individual experiments and suggest that $\gamma_{\mathrm{e}}<1$ (Lee et al., 2011, 2010). Therefore, model predictions for $C_{\mathrm{OA}}$-dependent mass thermograms are also reported for $\gamma_{\mathrm{e}}=0.001$ (Fig. 3b). As expected, the apparent volatility (i.e., extent of evaporation at a given temperature) is decreased compared to the $\gamma_{\mathrm{e}}=1$ case, and the simulated thermograms exhibit a greater similarity to the observations. Also, the extent of evaporation at room temperature is substantially lowered and more consistent with the observations, as now only species with $C^{*} \geq \sim 1000 \mu \mathrm{g} \mathrm{m}^{-3}$ will evaporate to any substantial extent in the TD due to vapor stripping alone. However, the simulations also indicate a very strong $C_{\mathrm{OA}}$ dependence - higher volatility with higher $C_{\mathrm{OA}}$ - is expected when $\gamma_{\mathrm{e}}=0.001$, which is inconsistent with the observations here. This demonstrates that conclusions regarding the magnitude of parameters such as $\gamma_{\mathrm{e}}$ when derived from single experiments may not provide a robust description of the process in question (here, evaporation) because they are not unique solutions (i.e., are dependent on the other model inputs, namely the assumed $\Delta H_{\text {vap }}$ and volatility distribution). Regardless of assumptions about mass transfer limitations, the model predictions for the mass thermograms of particles comprised entirely of monomers (i.e., based on the Pathak et al., 2007, volatility distribution) unambiguously show a dependence on $C_{\mathrm{OA}}$. Thus, there is a clear disconnect between volatility distributions derived from SOA growth experiments and observations from SOA evaporation experiments that cannot be entirely explained by kinetic limitations to evaporation.

\subsubsection{Dimer-decomposition model}

The above discrepancy strongly suggests that the molecular composition of the condensed phase is only indirectly related to the volatilities of the condensing species as determined from growth experiments. Here, the possibility that this discrepancy can be explained through the formation and subsequent decomposition of dimers (and higher-order oligomers) through condensed-phase reactions is examined. Cappa and Wilson (2011) demonstrated that, although simple applications of equilibrium absorption partitioning theory can explain SOA growth in laboratory chamber experiments, such models are not unique explanations. In particular, they showed it was possible to reconcile SOA growth experiments with the occurrence of condensed-phase reactions even to the extent that the entire particle is rapidly converted from monomers (which retain the volatility of the condensing species) to non-volatile species. There is now a variety of experimental evidence that many types of SOA particles are composed of a large fraction of oligomers (Kourtchev et al., 2014; Putman et al., 2012; Kundu et al., 2012; Gao et al., 

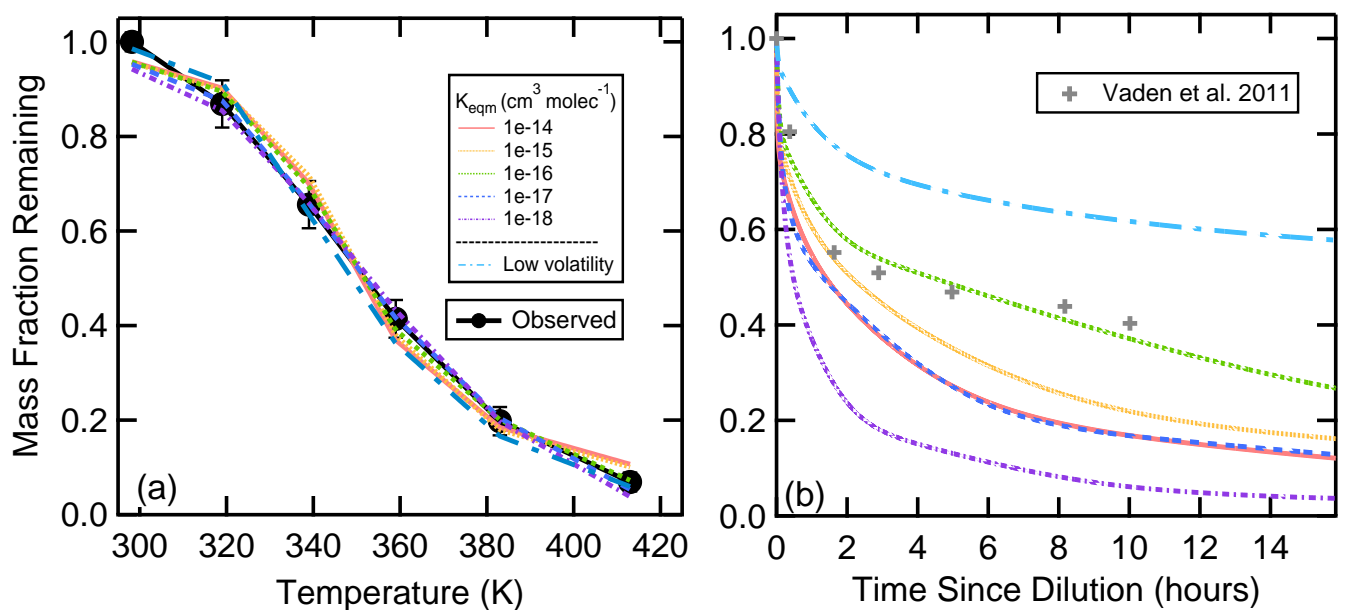

Figure 4. (a) Comparison between observed medium/low- $C_{\mathrm{OA}}$ grouping (black $\bullet$ ) and best-fit calculated mass thermograms for the TD model that includes dimer decomposition and for the low-volatility compound model. For the dimer-decomposition model, the concentration of dimers is much greater than the concentration of monomers. (b) Simulated isothermal, room-temperature evaporation based on the best-fit model parameters determined in (a). The initial SOA concentration was $100 \mu \mathrm{g} \mathrm{m}^{-3}$, which was diluted by a factor of 30 , and evaporated vapors were lost to the simulated chamber walls with a rate coefficient of $10^{-3} \mathrm{~s}^{-1}$. The grey crosses $(+)$ in panel (b) are the experimental data from the isothermal dilution of $\alpha$-pinene $+\mathrm{O}_{3} \mathrm{SOA}\left(d_{\mathrm{p}}=160 \mathrm{~nm}\right)$ from Vaden et al. (2011).

2004a; Muller et al., 2009; Kalberer et al., 2004), which will generally have volatilities lower than the monomeric precursors. For the system considered in this study, $\alpha$-pinene + $\mathrm{O}_{3}$ SOA, the oligomeric content is suggested to be greater than 50\% (Tolocka et al., 2004; Gao et al., 2004a, b; Hall and Johnston, 2012a), and both laboratory (Kristensen et al., 2014) and ambient (Kristensen et al., 2013; Yasmeen et al., 2010) measurements have identified several $\alpha$-pinene $+\mathrm{O}_{3}$ SOA dimers.

Simulated mass thermograms have been calculated as a function of $C_{\mathrm{OA}}$ using the modified TD model, in which some fraction of the condensed-phase material is assumed to exist as dimers. The same seven volatility bins were used with the same mass yields as the semi-volatile monomer case to calculate the initial concentration of monomers in the particle. As described above, the equilibrium coefficient, $K_{\text {eqm }}$, was used to determine the initial monomer-dimer equilibrium while the decomposition rate coefficient, $k_{\mathrm{r}}$, and activation energy, $\Delta E_{\mathrm{a}}$, describe the rate and sensitivity to temperature changes of dimer thermal decomposition. None of the parameters are known a priori. Since there is a relationship between all three parameters $\left(K_{\text {eqm }}=k_{\mathrm{f}} / k_{\mathrm{r}}\right.$ and $k_{\mathrm{r}}(T)$ are dependent on $\Delta E_{\mathrm{a}}$ ), we have taken the approach of specifying different values of $K_{\text {eqm }}$ and then fitting the model to the observations by adjusting $k_{\mathrm{r}}$ and $\Delta E_{\mathrm{a}}$. The level of model-measurement agreement for the different $K_{\text {eqm }}$ was then assessed.

The model aerosol used had $d_{\mathrm{p}}=90 \mathrm{~nm}$ and $C_{\mathrm{OA}}=$ $100 \mu \mathrm{g} \mathrm{m}^{-3}$ as starting conditions, and was fit to the average mass thermogram of the medium/low- $C_{\mathrm{OA}}$ grouping (Fig. 4a). Generally good fits were obtained for all $K_{\text {eqm }}$ over the range $10^{-18}$ to $10^{-14} \mathrm{~cm}^{3}$ molecule ${ }^{-1}$, with the overall best agreement obtained for $K_{\text {eqm }}=10^{-17} \mathrm{~cm}^{3}$ molecule ${ }^{-1}$, although the differences are quite small (see the Supplement for the best-fit model parameters for each $K_{\text {eqm }}$ ). At smaller $K_{\text {eqm }}$, extensive room-temperature evaporation occurred as a result of the increasing initial fraction of semivolatile monomers, a result that is inconsistent with the observations. However, even for the simulations at larger $K_{\text {eqm }}$, some evaporation at room temperature was always predicted. The simulated room-temperature evaporation at larger $K_{\text {eqm }}$ may result from the model assumption of liquid-like particles in that if mixing within the particles were slow such that there were a buildup at the particle surface of non-volatile dimers, then evaporation of monomers that are buried below the surface would be slowed (Roldin et al., 2014). The associated best fit $k_{\mathrm{r}}(298 \mathrm{~K})$ and $\Delta E_{\mathrm{a}}$ varied with $K_{\text {eqm }}$, from $1.6 \times 10^{-3} \mathrm{~s}^{-1}$ to $2.8 \times 10^{-2} \mathrm{~s}^{-1}$ and from 15 to $42 \mathrm{~kJ} \mathrm{~mol}^{-1}$, respectively; smaller $K_{\text {eqm }}$ values corresponded to larger $k_{\mathrm{r}}$ and smaller $\Delta E_{\mathrm{a}}$.

These $K_{\text {eqm }}$ values correspond to a case where the particles are almost entirely composed of dimers, as the dimer fraction is $>97 \%$ for all $K_{\text {eqm }}>10^{-18} \mathrm{~cm}^{3}$ molecule ${ }^{-1}$. The range of best-fit $k_{\mathrm{r}}$ indicates a dimer lifetime of only $1-$ $10 \mathrm{~min}$ with respect to decomposition at room temperature. The range of $k_{\mathrm{f}}$ values associated with the best fit $K_{\text {eqm }}$ and $k_{\mathrm{r}}$ is $1.6 \times 10^{-21}$ to $2.8 \times 10^{-16} \mathrm{~cm}^{3}$ molecule ${ }^{-1} \mathrm{~s}^{-1}$. Given a typical molecular density of $\sim 10^{21}$ molecules $\mathrm{cm}^{-3}$, the approximate dimer formation timescale is only a fraction of a second, consistent with the short reaction time in these experiments. Consequently, the dimer-decomposition timescale is not the same as the observable timescale associated with particle mass loss at room temperature upon, for example, 

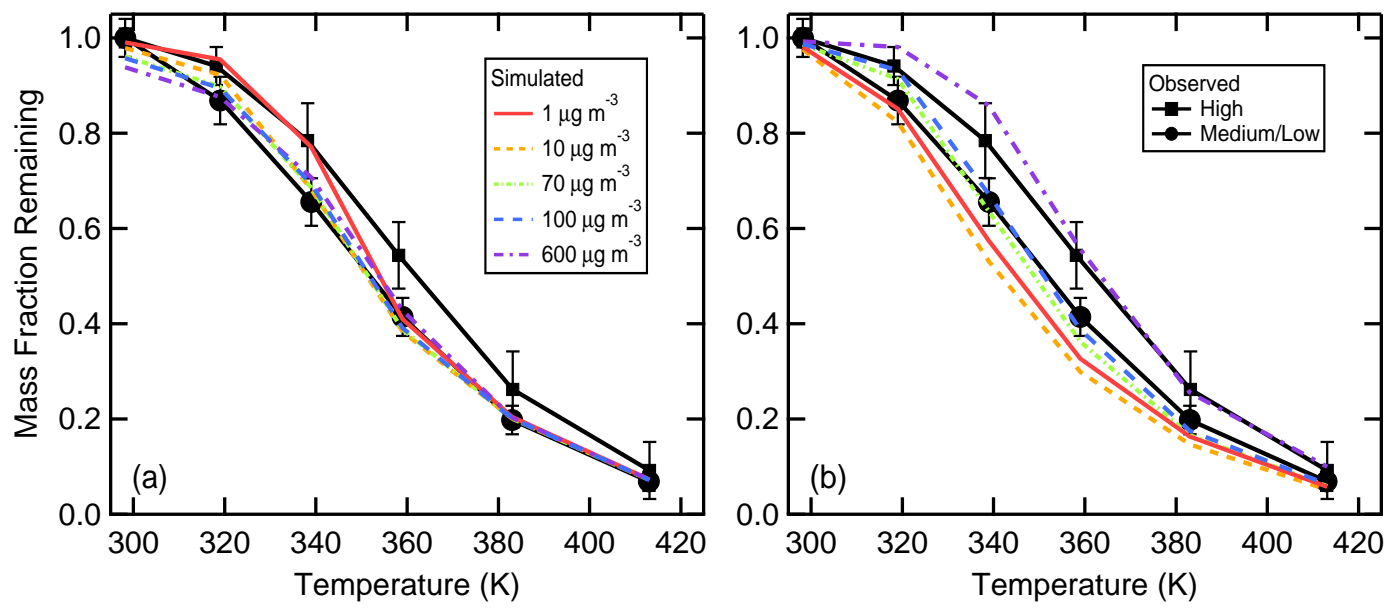

Figure 5. (a) Calculated mass thermograms for variable $C_{\mathrm{OA}}$ based on the best-fit parameters for the $K_{\text {eqm }}=10^{-16} \mathrm{~cm}^{3} \mathrm{molecule}^{-1} \mathrm{dimer}^{-}$ decomposition model as compared to the observations for the average medium/low and high $C_{\mathrm{OA}}$. (b) Same as (a) but for the best-fit low-volatility model.

isothermal dilution (Grieshop et al., 2007). However, there are several potential factors that slow down evaporation at room temperature despite the short dimer lifetime with respect to decomposition, as discussed below when isothermal dilution and evaporation is considered. The $K_{\text {eqm }}, k_{\mathrm{r}}$, and $\Delta E_{\mathrm{a}}$ determined above from fitting the medium/low$C_{\mathrm{OA}}$ data (i.e., $C_{\mathrm{OA}}=100 \mu \mathrm{g} \mathrm{m}^{-3}$ ) have been used to predict additional mass thermograms for $C_{\mathrm{OA}}=1,10,70$ and $600 \mathrm{\mu g} \mathrm{m}^{-3}$ (Fig. 5a). The predicted mass thermograms are mostly independent of $C_{\mathrm{OA}}$, in contrast with the semi-volatile monomer model. Thus, when the particle initially consists nearly entirely of dimers, this "dimer-decomposition" model result is generally consistent with the experimental observations, where limited differences were observed between the mass thermograms measured at different $C_{\mathrm{OA}}$, although it should be noted that the slight increase in $T_{50}$ observed at the highest mass loadings is not reproduced. Also, only the $C_{\mathrm{OA}}=1 \mu \mathrm{g} \mathrm{m}^{-3}$ simulation predicts negligible evaporation at room temperature, as was observed for all $C_{\mathrm{OA}}$. The dimerdecomposition model also predicts that the observable particle composition should remain relatively constant as evaporation is induced (Fig. 6a), consistent with observations. This prediction is consistent with previous measurements in which it was observed that the particle composition, as measured using a vacuum ultraviolet aerosol mass spectrometer (VUV-AMS) remained quite constant during the heatinginduced evaporation of $\alpha$-pinene $+\mathrm{O}_{3}$ SOA (Cappa and Wilson, 2011). There are several experiments where changes to composition were observed. Hall and Johnston (2012b) used an electrospray ionization Fourier transform ion cyclotron resonance (ESI-FTICR) mass spectrometer to measure the fraction of oligomers in the particle before and after heating $(393 \mathrm{~K})$ and found that the fraction of oligomers and the $\mathrm{O}: \mathrm{C}$ ratio increase after heating. Furthermore, when recondensation does occur, the compounds that recondensed ap- pear to be monomer decomposition products. Kostenidou et al. (2009) used a quadrupole AMS to quantify the mass fraction of $m / z 44$ fragments as a function of MFR and found that the fraction of $m / z 44$ increased as MFR decreased, indicating more oxygenated particles with heating-induced evaporation. Since the dimer model presented here tracks the relative concentration of dimers and monomers due to decomposition, the most comparable study is Cappa and Wilson (2011) because the measurement technique is one that primarily detects the monomer components due, most likely, to thermal degradation during analysis.

Trump and Donahue (2014) and Roldin et al. (2014) have previously suggested that accounting for the behavior of dimers within SOA can help to explain observations of SOA evaporation; our observations and analysis support and expand upon this conclusion. The range of $k_{\mathrm{r}}$ independently determined here is somewhat larger than the roomtemperature $k_{\mathrm{r}}$ suggested by Trump and Donahue (2014) $(=$ $\left.1.1 \times 10^{-4} \mathrm{~s}^{-1}\right)$ and Roldin et al. (2014) $\left(=2.8 \times 10^{-5} \mathrm{~s}^{-1}\right)$, which were based on needing an evaporation timescale of $\sim 1 \mathrm{~h}$ for isothermal evaporation (Grieshop et al., 2007; Vaden et al., 2011). Ultimately, reconciliation of the different timescales indicated for dimer decomposition between the different studies likely will require more detailed consideration of the exact nature of various dimer types with respect to their decomposition and formation timescales, which may not all be identical as assumed here, and of the influence of particle phase on evaporation. It should be noted that the $\Delta E_{\mathrm{a}}$ determined here are substantially smaller than that suggested by Trump and Donahue (2014), who give $E_{\mathrm{a}, \mathrm{r}} \sim 80 \mathrm{~kJ} \mathrm{~mol}^{-1}$ (and where, it seems, that their $E_{\mathrm{a}, \mathrm{r}}$ is essentially equal to the $\Delta E_{\mathrm{a}}$ here as they assume that $k_{\mathrm{f}}$ is temperature-independent). However, this difference can be understood by recognizing that they assumed a constant value for $A\left(=3 \times 10^{10} \mathrm{~s}^{-1}\right)$ and $k_{\mathrm{r}}(300 \mathrm{~K})$ and determined $E_{\mathrm{a}, \mathrm{r}}$ using the relationship $k_{\mathrm{r}}(T)$ 

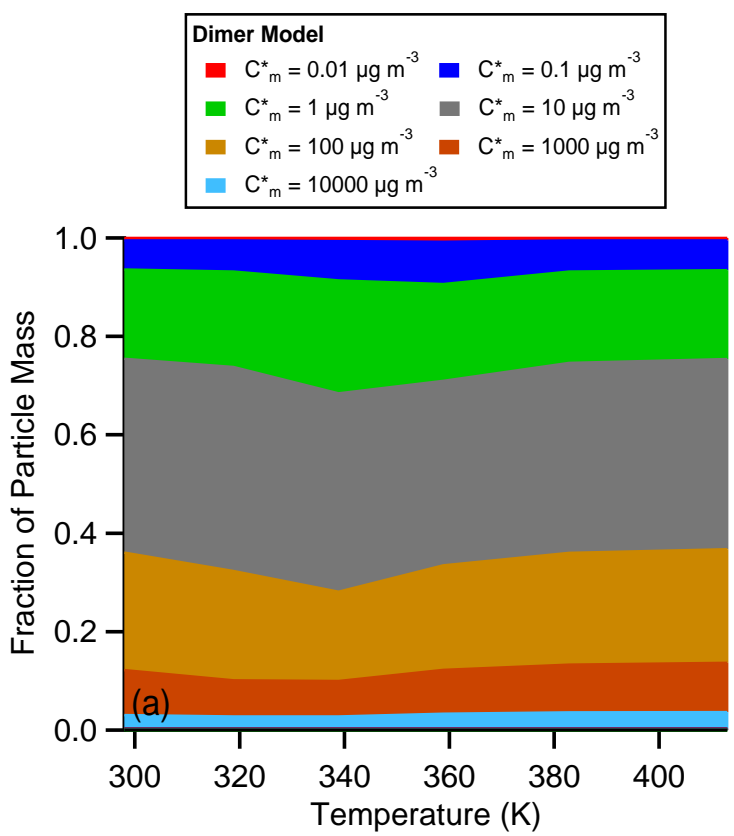

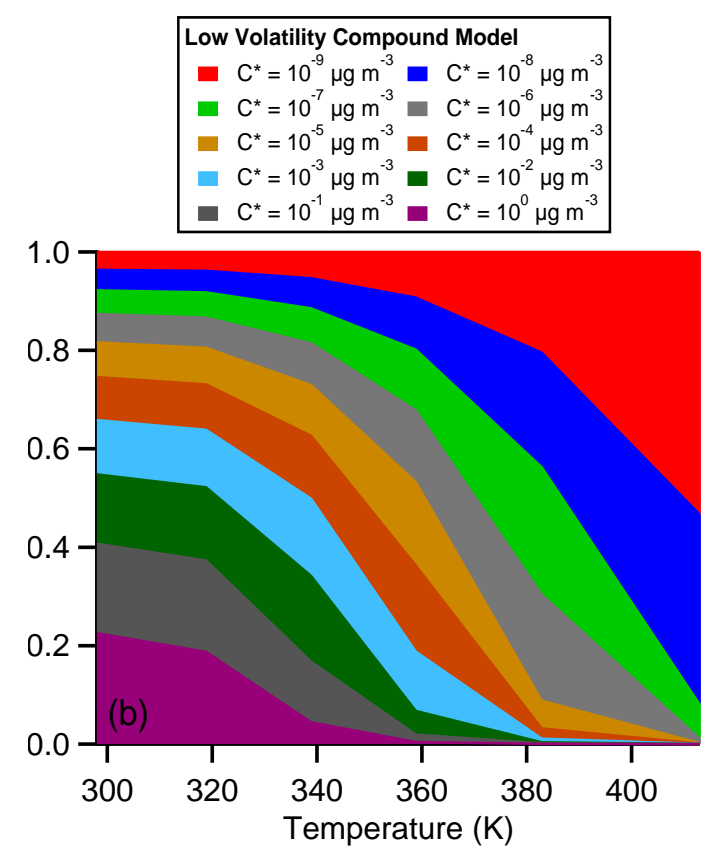

Figure 6. Variation in the relative particle composition with temperature from the (a) dimer-decomposition and (b) low-volatility monomer evaporation TD models. The colors correspond to the various dimer and monomer species, defined by the monomer $C^{*}$ values. For the dimerdecomposition model the monomer fractional contributions are too small to be seen, and the reported $C^{*}$ values in the legend correspond to the parent monomer values associated with each dimer. For the low-volatility monomer case, the $C^{*}$ values correspond to the actual evaporating monomer values. The simulations were run for an initial $C_{\mathrm{OA}}=100 \mu \mathrm{g} \mathrm{m}^{-3}$.

$=A \exp \left(-E_{\mathrm{a}, \mathrm{r}} / R T\right)$. Thus, underestimations of $k_{\mathrm{r}}$ may lead them to actually overestimate the true temperature sensitivity of the system.

The best-fit $K_{\text {eqm }}$ and $k_{\mathrm{r}}$ were determined from fitting to temperature-dependent evaporation experiments that occur over relatively short timescales $(\sim 1 \mathrm{~min})$ in the thermodenuder. To facilitate more direct connections with previous experiments that have investigated room-temperature evaporation upon dilution, the best-fit dimer-decomposition model for $K_{\text {eqm }}=10^{-17} \mathrm{~cm}^{3}$ molecule ${ }^{-1}$ has been used to simulate the long-time, isothermal, room-temperature evaporation of SOA for the case where the SOA is initially diluted and the evaporating vapors are constantly being stripped from the gas-phase (Fig. 4b). This corresponds approximately to the conditions in a series of experiments investigating SOA evaporation (Vaden et al., 2011; Wilson et al., 2015). A vapor loss rate constant of $k_{\text {loss }}=10^{-3} \mathrm{~s}^{-1}$ has been used, which is a reasonable estimate given the size of the chambers used in the previous experiments (Matsunaga and Ziemann, 2010; Zhang et al., 2014). The initial (pre-dilution) $C_{\mathrm{OA}}$ is $100 \mathrm{\mu g} \mathrm{m}^{-3}$, which was diluted by a factor of $\mathrm{DF}=30$ to induce evaporation.

The literature experiments have generally shown evidence for evaporation of SOA on fast, medium and slower timescales, where "fast" corresponds to timescales of around a minute, "medium" corresponds to timescales of around $1 \mathrm{~h}$ and "slow" to timescales of many hours. The dimer model simulations for all the $K_{\text {eqm }}$ fits exhibit similar behavior, with "fast", "medium" and "slow" periods of mass loss and timescales similar to previous observations. There is a nonmonotonic dependence on $K_{\text {eqm }}$, with the least mass loss predicted for $K_{\text {eqm }}=10^{-16} \mathrm{~cm}^{3}$ molecule ${ }^{-1}$ and greater total mass loss predicted for $K_{\text {eqm }}$ both larger and smaller. The behavior results from a balance between the $k_{\mathrm{r}}, k_{\mathrm{f}}$ and evaporation timescales for each $K_{\text {eqm }}$ fit. After $15 \mathrm{~h}$ the simulated MFR of SOA is 5-27\% of the initial (post-dilution) $C_{\mathrm{OA}}$. The general model behavior, which indicates that evaporation occurs on multiple timescales, can be understood by recognizing that decomposition of dimers composed of higher $C^{*}$ monomers leads to rapid evaporation, such that the observable evaporation rate is controlled by the dimer decomposition. In contrast, decomposition of dimers composed of lower $C^{*}$ monomers results in species that do evaporate, but only slowly at room temperature. Given a distribution of monomers with respect to their $C^{*}$, the result is a time-dependent evaporation profile with multiple apparent timescales for evaporation. Further, as evaporation proceeds, the finite rate of vapor loss means that over time the gasphase concentration may build up, which will also limit the rate of mass loss.

The simulated MFR values at the end of $15 \mathrm{~h}$ of SOA evaporation are somewhat lower than was observed in the literature experiments for dry, fresh SOA from $\alpha$-pinene $+\mathrm{O}_{3}$, where MFR $\sim 0.35-0.4$ at $15 \mathrm{~h}$ (Vaden et al., 2011; Wilson 

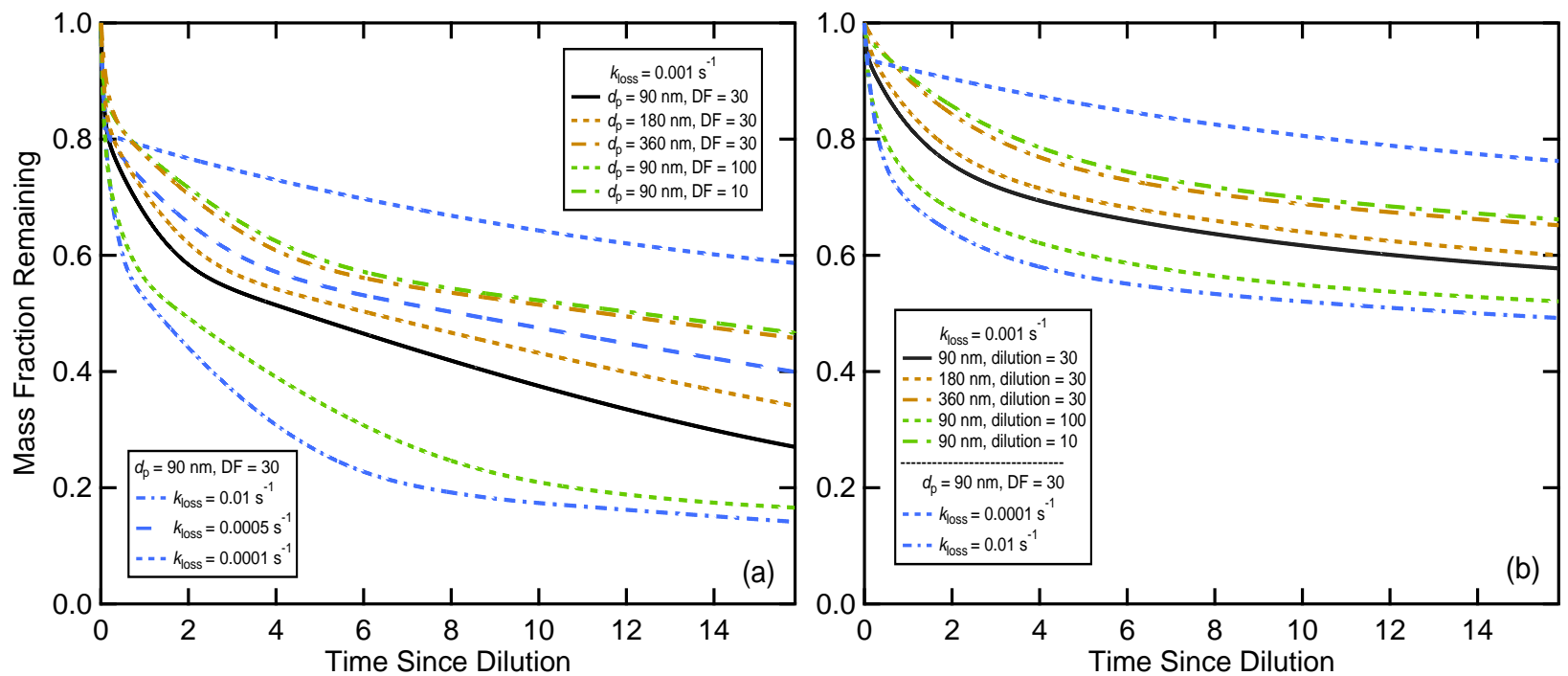

Figure 7. Dependence of the isothermal evaporation simulations on the assumed vapor loss rate $\left(k_{\text {loss }}\right)$, dilution factor (DF) or particle diameter $\left(d_{\mathrm{p}}\right)$ for (a) the dimer-decomposition and (b) the low-volatility models. All simulations were run for an initial $C_{\mathrm{OA}}=100 \mu \mathrm{g} \mathrm{m}^{-3}$. For the dimer-decomposition model, the $K_{\text {eqm }}=10^{-16} \mathrm{~cm}^{3}$ molecule -1 best-fit results were used.

et al., 2015). However, the extent of evaporation is dependent on the model assumptions, specifically the $k_{\mathrm{loss}}$ and DF. Smaller $k_{\text {loss }}$ or DF leads to larger MFR at a given time due to more extensive inhibition of evaporation resulting from faster saturation of the gas-phase (Fig. 7a). Conversely, larger $k_{\text {loss }}$ or DF lead to more extensive evaporation. As neither the $k_{\text {loss }}$ nor DF is explicitly reported in the literature experiments, a more quantitative comparison is not possible. However, it is nonetheless noteworthy that the model suggests that both $k_{\text {loss }}$ and DF can play a controlling role in observations of isothermal evaporation. These previous isothermal evaporation measurements also indicate that SOA evaporation is mostly size-independent, in contrast to evaporation of singlecomponent particles (Vaden et al., 2011; Wilson et al., 2015). Simulations using the dimer-decomposition model with different starting particle sizes show some dependence on particle size $\left(d_{\mathrm{p}}=90,180\right.$ and $\left.360 \mathrm{~nm}\right)$, with larger particles having smaller MFRs at a given time (Fig. 7a). However, the overall differences are relatively small and reasonably consistent with the observations given that the observations have typically considered a narrower size range than examined here.

\subsubsection{Low-volatility SOA model}

One alternative possibility to explain the observations of evaporation of SOA in the TD is that the observed heatinginduced evaporation results from direct evaporation of lowvolatility species. These low-volatility species could be either highly oxygenated monomers (Ehn et al., 2014) or thermally stable dimers or higher-order oligomers, although the thermal stability of dimers seems unlikely (Hall and Johnston, 2012a). To test this idea, the TD model has been fit to the observations assuming that the particles are only composed of semi-volatile and low-volatility species, but where the volatility distribution is skewed to much lower $C^{*}$ than suggested from SOA growth experiments (i.e., from the Pathak et al., 2007, volatility distribution). Given that there is negligible evaporation observed at room temperature in the TD for all $C_{\mathrm{OA}}$, including $C_{\mathrm{OA}}=1 \mu \mathrm{g} \mathrm{m}^{-3}$, the highest volatility bin was set at $C^{*}=1 \mu \mathrm{g} \mathrm{m}^{-3}$. The lowest value was set based on the requirement that there remains some particle mass at $\sim 343 \mathrm{~K}$. If $\Delta H_{\text {vap }}$ is too large then even very lowvolatility compounds will not persist to such high temperatures (Cappa and Jimenez, 2010; Cappa, 2010). As such, an upper-limit $\Delta \mathrm{H}_{\mathrm{vap}}$ constraint of $185 \mathrm{~kJ} \mathrm{~mol}^{-1}$ was placed on the $C^{*} / \Delta \mathrm{H}_{\text {vap }}$ parameterization, and a lower bound $C^{*}$ of $10^{-9} \mathrm{\mu g} \mathrm{m}^{-3}$ was used. Following Cappa and Jimenez (2010), a relationship between the total organic mass and $C^{*}$ was assumed, where $C_{i, \text { tot }}=a_{1}+a_{2} \exp \left[a_{3}\left(\log \left(C^{*}\right)+a_{4}\right)\right]$. Values of the $a_{x}$ parameters have been determined through data fitting; it is difficult to constrain the absolute $C_{\mathrm{OA}}$ while determining the $a_{x}$ parameters through fitting, and thus $C_{\mathrm{OA}}$ was allowed to vary. The model was fit to the average thermogram for the medium/low- $C_{\mathrm{OA}}$ grouping, and a good fit was found when $a_{x}=[1.53,8.5,0.3,0.59]$, with a corresponding $C_{\mathrm{OA}}$ of $71 \mu \mathrm{g} \mathrm{m}^{-3}$ (Fig. $4 \mathrm{a}$ ). This demonstrates that an alternative model can potentially be used to explain the TD results, namely one in which the condensed-phase species are very low volatility but evaporate directly in response to heating.

If the same $a_{x}$ distribution is used, but with $C_{i, \text { tot }}$ scaled up or down to give a different initial $C_{\mathrm{OA}}$ (and slightly different distribution of compounds), the simulated volatility de- 
creases slightly as $C_{\mathrm{OA}}$ increases (Fig. 5b). This is mostly due to gas-phase saturation at higher concentrations, and subsequently greater recondensation as the SOA cools in the denuder. Nonetheless, this contrasts with the $C_{\mathrm{OA}}$ dependence predicted by the semi-volatile monomer model and is in the same direction of the observations, where the high$C_{\mathrm{OA}}$ grouping exhibited lower apparent volatility. There is, however, some difference in the simulated mass thermograms for low and medium $C_{\mathrm{OA}}$, which was not observed, although the gap between the low $\left(1-10 \mu \mathrm{g} \mathrm{m}^{-3}\right)$ and medium $\left(100 \mu \mathrm{g} \mathrm{m}^{-3}\right) C_{\mathrm{OA}}$ simulations is smaller than the gap between the medium and high $\left(600 \mu \mathrm{g} \mathrm{m}^{-3}\right) C_{\mathrm{OA}}$ simulations. If recondensation of the evaporated species were, for some reason, not particularly efficient (due perhaps to changes in the molecular composition upon heating) then the differences between the different $C_{\mathrm{OA}}$ simulations would be lessened.

As with the dimer-decomposition model, simulation of isothermal evaporation by the low-volatility monomer model provides evidence for multiple evaporation timescales, with "fast", "medium" and "slow" components (Fig. 4b). For the same $k_{\text {loss }}\left(=10^{-3} \mathrm{~s}^{-1}\right)$ and DF $(=30)$, the extent of evaporation from the low-volatility aerosol simulation at $15 \mathrm{~h}$ is less than for the various dimer-decomposition simulations. The low-volatility aerosol model exhibits a similar sensitivity to the assumed $k_{\text {loss }}$ and DF, and a slightly smaller sensitivity to changes in particle size (Fig. 7b). It is apparent that the low-volatility aerosol model is compatible with the observations from both our TD and the literature isothermal evaporation experiments (Vaden et al., 2011; Wilson et al., 2015).

Although both the low-volatility aerosol and dimerdecomposition models perform equally well in explaining the observed mass thermograms and literature observations of isothermal evaporation, there is a distinct difference between two model results in terms of how the particle composition is predicted to vary with temperature. Unlike the dimer-decomposition model, the predicted relative particle composition undergoes substantial changes as the particles evaporate upon heating for the low-volatility aerosol model (Fig. 6b). This model result would suggest that potentially large changes in composition should be observed upon heating or, more generically, evaporation. This prediction is inconsistent with the various observations that suggest negligible to very moderate changes in the observed particle composition (Cappa and Wilson, 2011; Kostenidou et al., 2009).

\subsubsection{Comparison between model results}

Overall, the dimer-decomposition model of evaporation provides the most comprehensive explanation in that it can explain not only the current results where the observed mass thermograms are nearly independent of $C_{\mathrm{OA}}$ but also the minor changes in composition that occur upon heating-induced evaporation of $\alpha$-pinene $+\mathrm{O}_{3}$ SOA observed by some (e.g., Cappa and Wilson, 2011), the moderately long timescales required for achieving equilibrium upon isothermal dilution (e.g., Grieshop et al., 2007), and the bimodality of SOA evaporation upon rapid dilution and subsequent continuous vapor stripping (e.g., Vaden et al., 2011). The low-volatility monomer evaporation model can reproduce many of these observations, but suggests large compositional changes upon heating. The semi-volatile monomer model fails to reproduce nearly all of the observations. Additionally, the dimerdecomposition model is potentially consistent with suggestions that SOA particles formed under dry conditions have very high viscosity (Kannosto et al., 2013; Virtanen et al., 2010; Abramson et al., 2013). The viscosity of SOA should decrease rapidly as temperature increases and, to the extent that SOA might actually be a glass, could go through a glassliquid transition (Koop et al., 2011). If the particles were primarily semi-volatile monomers for which evaporation were limited by diffusion in the particle phase, then decreases in viscosity should lead to substantial increases in the observed evaporation rate (Zaveri et al., 2014; Roldin et al., 2014). The continuous change in VFR with temperature out to relatively high temperatures suggests that the condensed-phase species must have low volatility such that as the viscosity decreases there is no substantial impact on the observed particle evaporation. This model-observation comparison suggests that for $\mathrm{SOA}$ - at least that produced from the $\alpha$-pinene $+\mathrm{O}_{3}$ reaction - the mass thermogram does not give direct information on the distribution of volatilities of the original condensing compounds (i.e., the monomers) but on the properties of the oligomers, specifically their thermal stability. One limitation of the current kinetic model is the assumption that $k_{\mathrm{r}}$ and $\Delta E_{\mathrm{a}}$ are the same for all dimers, whereas it is likely that the rate and temperature sensitivity of oligomer decomposition is compound-specific (Hall and Johnston, 2012b). However, expansion of the model to include such information would only add more tunable parameters, and would not materially influence the conclusions here.

Despite the general success of the dimer-decomposition model in reproducing a variety of observations, it does predict some particle evaporation at room temperature in the TD, which was not observed. Further, it seems unlikely that all particle mass is converted to dimers on such rapid timescales as implied by the dimer-decomposition model; although accurate quantification of the relative fractions of dimers (and larger oligomers) versus monomers in SOA particles has proven challenging, it seems likely that the oligomer fraction is not $100 \%$ (Hall and Johnston, 2012b; Kalberer et al., 2004; Kristensen et al., 2014). Some experiments have observed apparent variations in VFR, determined from either heating or vapor stripping, as the particles are "aged" by sitting in the dark (Abramson et al., 2013) or by exposure to oxidants (Kalberer et al., 2004; Salo et al., 2011; Emanuelsson et al., 2013), suggesting that compositional changes (including dimer or oligomer formation) may occur on multiple timescales, ranging from seconds to minutes to hours. It therefore seems likely that a more complete representa- 
tion of $\alpha$-pinene $+\mathrm{O}_{3}$ SOA volatility is some hybrid of the dimer-decomposition and low-volatility species frameworks, where some substantial fraction of the condensed phase mass exists as very low-volatility, effectively non-volatile, dimers or oligomers - or even thermally unstable, low-volatility monomers - that decompose to produce species with a distribution of volatilities that subsequently evaporate, while some fraction exists as low-volatility $\left(C^{*}<1 \mu \mathrm{g} \mathrm{m}^{-3}\right)$ species that can directly evaporate but for which the actual volatilities tend to be lower than those predicted from traditional analyses of growth experiments. Regardless of the details, the effective volatility of $\alpha$-pinene $+\mathrm{O}_{3}$ is much less than predicted by growth experiments.

\section{Conclusions}

Experimental observations of temperature-dependent SOA evaporation have been presented that demonstrate that the apparent volatility of $\alpha$-pinene $+\mathrm{O}_{3}$ SOA, as characterized by heating in a thermodenuder, is mostly independent of the SOA concentration over many orders of magnitude variation. Comparison of these observations with various kinetic models of evaporation in the TD suggests that the observations are most consistent with SOA from the ozonolysis of $\alpha$-pinene being composed of a large fraction of effectively non-volatile but thermally unstable species; these species are likely dimers or higher-order oligomers, but could also be exceptionally low volatility monomers. Any monomers that do exist must be of sufficiently low volatility $\left(<\sim 1 \mu \mathrm{g} \mathrm{m}^{-3}\right)$ that they do not readily evaporate at room temperature. A dimer-decomposition model provided a good fit to the experimental observations when the monomer-dimer equilibrium constant ranged from $K_{\text {eqm }}$ $\sim 10^{-18}$ to $10^{-14} \mathrm{~cm}^{3}$ molecule ${ }^{-1}$, with corresponding rate coefficients for the reverse (decomposition) reaction ranging from $k_{\mathrm{r}}(298 \mathrm{~K})=1.6 \times 10^{-3}$ to $2.8 \times 10^{-2} \mathrm{~s}^{-1}$, and a difference in activation energies between the forward and reverse rate coefficients ranging from $\Delta E_{\mathrm{a}}=15$ to $42 \mathrm{~kJ} \mathrm{~mol}^{-1}$. The best-fit dimer-decomposition model can also explain observations of slow rates of evaporation after isothermal dilution (Vaden et al., 2011; Wilson et al., 2015) and nearly constant composition as a function of rapid heating (Cappa and Wilson, 2011). These parameters would, by themselves, suggest that the SOA particles are nearly entirely composed of dimers, which seems unlikely. However, a model in which the particle was assumed to be composed of lowvolatility compounds - either highly oxygenated monomers or oligomers - was shown to explain the bulk evaporation observations nearly as well, although it also indicated that large changes to particle composition upon heating should have been observed. Thus, it seems that a hybrid model where the particles are composed of a substantial fraction of dimers (or oligomers) and some smaller fraction of low-volatility compounds may ultimately provide a more complete description.
Many laboratory (Cappa and Wilson, 2011; Emanuelsson et al., 2013; Loza et al., 2013; Grieshop et al., 2007; Saleh et al., 2013) and field studies (Cappa and Jimenez, 2010) have aimed to characterize the volatility of SOA. In general, the observations have concluded that the effective volatility of SOA is much lower than the volatility determined from interpretation of formation studies within a gas-particle partitioning framework. The analysis presented here suggests that this apparent discrepancy can be reconciled to a large extent through a combined framework in which the volatility distributions derived from growth experiments (i.e., Pathak et al., 2007) provides a reasonable description of the properties of the condensing monomers, but where rapid formation of thermally unstable dimers (and higher-order oligomers) occurs, which consequently suppresses the apparent volatility of the SOA. Since the residence time in our flowtube was $\sim 1 \mathrm{~min}$, these accretion reactions must occur on a similar timescale (or faster). This dimer formation timescale is much faster than what is typically used within air quality models (Carlton et al., 2010), which assume timescales on the order of a day, and suggests that air quality models may therefore have SOA that is too volatile and thus overly sensitive to dilution. However, care must be taken in the implementation of any model that allows for such rapid formation of dimers, as the ultimate consequence would be the transferal of all semivolatile material to the condensed phase. One possible reconciliation is that SOA particles may actually have a very high viscosity (which is, perhaps, a consequence of oligomer formation), which can limit the transport of gas-phase material into the particle bulk and the timescale and extent of transfer of gas-phase material into the particles (Zaveri et al., 2014). Although the oligomeric content of ambient biogenic SOA may be less than in laboratory biogenic SOA (Kourtchev et al., 2014), the presence of oligomers has been observed in both and needs to be accounted for in models of SOA volatility.

\section{The Supplement related to this article is available online at doi:10.5194/acp-15-9327-2015-supplement.}

Author contributions. K. R. Kolesar and C. D. Cappa designed the experiments and D. Johnson carried them out. C. Chen characterized the temperature profile in the thermodenuder. C. D. Cappa and K. R. Kolesar modified the kinetic model of evaporation from Cappa (2010) and performed the simulations. K. R. Kolesar and C. D. Cappa prepared the manuscript.

Acknowledgements. Special thanks to Anthony Kong for his assistance in running laboratory experiments. Funding for this work was provided by the National Science Foundation (ATM-1151062). K. R. Kolesar was partially supported by a fellowship from the UC 
Davis Atmospheric Aerosols and Health program.

Edited by: A. Virtanen

\section{References}

Abramson, E., Imre, D., Beranek, J., Wilson, J., and Zelenyuk, A.: Experimental determination of chemical diffusion within secondary organic aerosol particles, Phys. Chem. Chem. Phys., 15, 2983-2991, doi:10.1039/c2cp44013j, 2013.

Andreae, M. O. and Crutzen, P. J.: Atmospheric aerosols: Biogeochemical sources and role in atmospheric chemistry, Science, 276, 1052-1058, doi:10.1126/science.276.5315.1052, 1997.

Cappa, C. D.: A model of aerosol evaporation kinetics in a thermodenuder, Atmospheric Measurement Techniques, 3, 579-592, 10.5194/amt-3-579-2010, 2010.

Cappa, C. D. and Jimenez, J. L.: Quantitative estimates of the volatility of ambient organic aerosol, Atmos. Chem. Phys., 10, 5409-5424, doi:10.5194/acp-10-5409-2010, 2010.

Cappa, C. D. and Wilson, K. R.: Evolution of organic aerosol mass spectra upon heating: implications for OA phase and partitioning behavior, Atmos. Chem. Phys., 11, 1895-1911, doi:10.5194/acp11-1895-2011, 2011.

Carlton, A. G., Bhave, P. V., Napelenok, S. L., Edney, E. D., Sarwar, G., Pinder, R. W., Pouliot, G. A., and Houyoux, M.: Model Representation of Secondary Organic Aerosol in CMAQv4.7, Environ. Sci. Technol., 44, 8553-8560, doi:10.1021/es100636q, 2010.

Chen, Y. Y., Ebenstein, A., Greenstone, M., and Li, H. B.: Evidence on the impact of sustained exposure to air pollution on life expectancy from China's Huai River policy, Proc. Natl. Aca. Sci. USA, 110, 12936-12941, doi:10.1073/pnas.1300018110, 2013.

Donahue, N. M., Robinson, A. L., Stanier, C. O., and Pandis, S. N.: Coupled partitioning, dilution, and chemical aging of semivolatile organics, Environ. Sci. Technol., 40, 02635-02643, doi:10.1021/es052297c, 2006.

Ehn, M., Thornton, J. A., Kleist, E., Sipila, M., Junninen, H., Pullinen, I., Springer, M., Rubach, F., Tillmann, R., Lee, B., LopezHilfiker, F., Andres, S., Acir, I.-H., Rissanen, M., Jokinen, T., Schobesberger, S., Kangasluoma, J., Kontkanen, J., Nieminen, T., Kurten, T., Nielsen, L. B., Jorgensen, S., Kjaergaard, H. G., Canagaratna, M., Maso, M. D., Berndt, T., Petaja, T., Wahner, A., Kerminen, V.-M., Kulmala, M., Worsnop, D. R., Wildt, J., and Mentel, T. F.: A large source of low-volatility secondary organic aerosol, Nature, 506, 476-479, doi:10.1038/nature13032, 2014.

Emanuelsson, E. U., Watne, A. K., Lutz, A., Ljungstrom, E., and Hallquist, M.: Influence of Humidity, Temperature, and Radicals on the Formation and Thermal Properties of Secondary Organic Aerosol (SOA) from Ozonolysis of beta-Pinene, J. Phys. Chem. A, 117, 10346-10358, doi:10.1021/jp4010218, 2013.

Epstein, S. A., Riipinen, I., and Donahue, N. M.: A Semiempirical Correlation between Enthalpy of Vaporization and Saturation Concentration for Organic Aerosol, Environ. Sci. Technol., 44, 743-748, doi:10.1021/es902497z, 2010.

Fuentes, E. and McFiggans, G.: A modeling approach to evaluate the uncertainty in estimating the evaporation behaviour and volatility of organic aerosols, Atmos. Meas. Tech., 5, 735-757, doi:10.5194/amt-5-735-2012, 2012.

Gao, S., Keywood, M., Ng, N. L., Surratt, J., Varutbangkul, V., Bahreini, R., Flagan, R. C., and Seinfeld, J. H.: Low-molecularweight and oligomeric components in secondary organic aerosol from the ozonolysis of cycloalkenes and alpha-pinene, J. Phys. Chem. A, 108, 10147-10164, doi:10.1021/jp047466e, 2004a.

Gao, S., Ng, N. L., Keywood, M., Varutbangkul, V., Bahreini, R., Nenes, A., He, J. W., Yoo, K. Y., Beauchamp, J. L., Hodyss, R. P., Flagan, R. C., and Seinfeld, J. H.: Particle phase acidity and oligomer formation in secondary organic aerosol, Environ. Sci Technol., 38, 6582-6589, doi:10.1021/es049125k, 2004b.

Grieshop, A. P., Donahue, N. M., and Robinson, A. L.: Is the gas-particle partitioning in alpha-pinene secondary organic aerosol reversible?, Geophys. Res. Lett., 34, L14810, doi:10.1029/2007gl029987, 2007.

Guenther, A., Hewitt, C. N., Erickson, D., Fall, R., Geron, C., Graedel, T., Harley, P., Klinger, L., Lerdau, M., McKay, W. A., Pierce, T., Scholes, B., Steinbrecher, R., Tallamraju, R., Taylor, J., and Zimmerman, P.: A Global-Model of Natural Volatile Organic-Compound Emissions, J. Geophys. Res.-Atmos., 100, 8873-8892, doi:10.1029/94jd02950, 1995.

Hall, W. A. and Johnston, M. V.: Oligomer Formation Pathways in Secondary Organic Aerosol from MS and MS/MS Measurements with High Mass Accuracy and Resolving Power, J. Am. Soc. Mass Spectrom., 23, 1097-1108, doi:10.1007/s13361-0120362-6, 2012a.

Hall, W. A. and Johnston, M. V.: The ThermalStability of Oligomers in Alpha-Pinene Secondary Organic Aerosol, Aerosol Sci. Technol., 46, 983-989, doi:10.1080/02786826.2012.685114, 2012b.

Hallquist, M., Wenger, J. C., Baltensperger, U., Rudich, Y., Simpson, D., Claeys, M., Dommen, J., Donahue, N. M., George, C., Goldstein, A. H., Hamilton, J. F., Herrmann, H., Hoffmann, T., Iinuma, Y., Jang, M., Jenkin, M. E., Jimenez, J. L., Kiendler-Scharr, A., Maenhaut, W., McFiggans, G., Mentel, Th. F., Monod, A., Prévôt, A. S. H., Seinfeld, J. H., Surratt, J. D., Szmigielski, R., and Wildt, J.: The formation, properties and impact of secondary organic aerosol: current and emerging issues, Atmos. Chem. Phys., 9, 5155-5236, doi:10.5194/acp-9-51552009, 2009.

Han, Y. M., Iwamoto, Y., Nakayama, T., Kawamura, K., and Mochida, M.: Formation and evolution of biogenic secondary organic aerosol over a forest site in Japan, J. Geophys. Res.Atmos., 119, 259-273, doi:10.1002/2013jd020390, 2014.

Henry, K. M., Lohaus, T., and Donahue, N. M.: Organic Aerosol Yields from alpha-Pinene Oxidation: Bridging the Gap between First-Generation Yields and Aging Chemistry, Environ. Sci. Technol., 46, 12347-12354, doi:10.1021/es302060y, 2012.

Huffman, J. A., Ziemann, P. J., Jayne, J. T., Worsnop, D. R., and Jimenez, J. L.: Development and characterization of a fast-stepping/scanning thermodenuder for chemically-resolved aerosol volatility measurements, Aerosol Sci. Technol., 42, 395407, doi:10.1080/02786820802104981, 2008.

IPCC (Intergovernmental Panel on Climate Change): Climate Change 2014: Mitigation of Climate Change. Contribution of Working Group III to the Fifth Assessment Report of the Intergovernmental Panel on Climate Change, Cambridge University Press, Cambridge, UK and New York, 2014. 
Kalberer, M., Paulsen, D., Sax, M., Steinbacher, M., Dommen, J., Prevot, A. S. H., Fisseha, R., Weingartner, E., Frankevich, V., Zenobi, R., and Baltensperger, U.: Identification of polymers as major components of atmospheric organic aerosols, Science, 303, 1659-1662, 10.1126/science.1092185, 2004.

Kannosto, J., Yli-Pirila, P., Hao, L. Q., Leskinen, J., Jokiniemi, J., Makela, J. M., Joutsensaari, J., Laaksonen, A., Worsnop, D. R., Keskinen, J., and Virtanen, A.: Bounce characteristics of alpha-pinene-derived SOA particles with implications to physical phase, Boreal Environ. Res., 18, 329-340, 2013.

Karnezi, E., Riipinen, I., and Pandis, S. N.: Measuring the atmospheric organic aerosol volatility distribution: a theoretical analysis, Atmos. Meas. Tech., 7, 2953-2965, doi:10.5194/amt7-2953-2014, 2014.

Kesselmeier, J. and Staudt, M.: Biogenic volatile organic compounds (VOC): An overview on emission, physiology and ecology, J. Atmos. Chem., 33, 23-88, doi:10.1023/a:1006127516791, 1999.

Koop, T., Bookhold, J., Shiraiwa, M., and Poschl, U.: Glass transition and phase state of organic compounds: Dependency on molecular properties and implications for secondary organic aerosols in the atmosphere, Phys. Chem. Chem. Phys., 13, 19238-19255, doi:10.1039/c1cp22617g, 2011.

Kostenidou, E., Lee, B. H., Engelhart, G. J., Pierce, J. R., and Pandis, S. N.: Mass Spectra Deconvolution of Low, Medium, and High Volatility Biogenic Secondary Organic Aerosol, Environ. Sci. Technol., 43, 4884-4889, doi:10.1021/es803676g, 2009.

Kourtchev, I., Fuller, S. J., Giorio, C., Healy, R. M., Wilson, E., O'Connor, I., Wenger, J. C., McLeod, M., Aalto, J., Ruuskanen, T. M., Maenhaut, W., Jones, R., Venables, D. S., Sodeau, J. R., Kulmala, M., and Kalberer, M.: Molecular composition of biogenic secondary organic aerosols using ultrahigh-resolution mass spectrometry: comparing laboratory and field studies, Atmos. Chem. Phys., 14, 2155-2167, doi:10.5194/acp-14-21552014, 2014.

Kristensen, K., Enggrob, K. L., King, S. M., Worton, D. R., Platt, S. M., Mortensen, R., Rosenoern, T., Surratt, J. D., Bilde, M., Goldstein, A. H., and Glasius, M.: Formation and occurrence of dimer esters of pinene oxidation products in atmospheric aerosols, Atmos. Chem. Phys., 13, 3763-3776, doi:10.5194/acp-13-37632013, 2013.

Kristensen, K., Cui, T., Zhang, H., Gold, A., Glasius, M., and Surratt, J. D.: Dimers in $\alpha$-pinene secondary organic aerosol: effect of hydroxyl radical, ozone, relative humidity and aerosol acidity, Atmos. Chem. Phys., 14, 4201-4218, doi:10.5194/acp-14-42012014, 2014.

Kundu, S., Fisseha, R., Putman, A. L., Rahn, T. A., and Mazzoleni, L. R.: High molecular weight SOA formation during limonene ozonolysis: insights from ultrahigh-resolution FT-ICR mass spectrometry characterization, Atmos. Chem. Phys., 12, 5523-5536, doi:10.5194/acp-12-5523-2012, 2012.

Lee, B. H., Kostenidou, E., Hildebrandt, L., Riipinen, I., Engelhart, G. J., Mohr, C., DeCarlo, P. F., Mihalopoulos, N., Prevot, A. S. H., Baltensperger, U., and Pandis, S. N.: Measurement of the ambient organic aerosol volatility distribution: application during the Finokalia Aerosol Measurement Experiment (FAME2008), Atmos. Chem. Phys., 10, 12149-12160, doi:10.5194/acp10-12149-2010, 2010.
Lee, B. H., Pierce, J. R., Engelhart, G. J., and Pandis, S. N.: Volatility of secondary organic aerosol from the ozonolysis of monoterpenes, Atmos. Environ., 45, 2443-2452, doi:10.1016/j.atmosenv.2011.02.004, 2011.

Loza, C. L., Coggon, M. M., Nguyen, T. B., Zuend, A., Flagan, R. C., and Seinfeld, J. H.: On the Mixing and Evaporation of Secondary Organic Aerosol Components, Environ. Sci. Technol., 47, 6173-6180, doi:10.1021/es400979k, 2013.

Matsunaga, A. and Ziemann, P. J.: Yields of beta-hydroxynitrates, dihydroxynitrates, and trihydroxynitrates formed from $\mathrm{OH}$ radical-initiated reactions of 2-methyl-1-alkenes, Proc. Natl. Aca. Sci. USA, 107, 6664-6669, doi:10.1073/pnas.0910585107, 2010.

Muller, L., Reinnig, M. C., Hayen, H., and Hoffmann, T.: Characterization of oligomeric compounds in secondary organic aerosol using liquid chromatography coupled to electrospray ionization Fourier transform ion cyclotron resonance mass spectrometry, Rapid Comm. Mass Spectrom., 23, 971-979, doi:10.1002/rcm.3957, 2009.

Odum, J. R., Hoffmann, T., Bowman, F., Collins, D., Flagan, R. C., and Seinfeld, J. H.: Gas/particle partitioning and secondary organic aerosol yields, Environ. Sci. Technol., 30, 2580-2585, 1996.

Pankow, J. F.: An Absorption-Model of the Gas Aerosol Partitioning Involved in the Formation of Secondary Organic Aerosol, Atmos. Environ., 28, 189-193, 1994.

Pathak, R. K., Presto, A. A., Lane, T. E., Stanier, C. O., Donahue, N. M., and Pandis, S. N.: Ozonolysis of a-pinene: parameterization of secondary organic aerosol mass fraction, Atmos. Chem. Phys., 7, 3811-3821, doi:10.5194/acp-7-3811-2007, 2007.

Putman, A. L., Offenberg, J. H., Fisseha, R., Kundu, S., Rahn, T. A., and Mazzoleni, L. R.: Ultrahigh-resolution FT-ICR mass spectrometry characterization of alphapinene ozonolysis SOA, Atmos. Environ., 46, 164-172, doi:10.1016/j.atmosenv.2011.10.003, 2012.

Riipinen, I., Pierce, J. R., Donahue, N. M., and Pandis, S. N.: Equilibration time scales of organic aerosol inside thermodenuders: Evaporation kinetics versus thermodynamics, Atmos. Environ., 44, 597-607, doi:10.1016/j.atmosenv.2009.11.022, 2010.

Roldin, P., Eriksson, A. C., Nordin, E. Z., Hermansson, E., Mogensen, D., Rusanen, A., Boy, M., Swietlicki, E., Svenningsson, B., Zelenyuk, A., and Pagels, J.: Modelling non-equilibrium secondary organic aerosol formation and evaporation with the aerosol dynamics, gas- and particle-phase chemistry kinetic multilayer model ADCHAM, Atmos. Chem. Phys., 14, 7953-7993, doi:10.5194/acp-14-7953-2014, 2014.

Saleh, R., Shihadeh, A., and Khlystov, A.: On transport phenomena and equilibration time scales in thermodenuders, Atmos. Meas. Tech., 4, 571-581, doi:10.5194/amt-4-571-2011, 2011.

Saleh, R., Donahue, N. M., and Robinson, A. L.: Time Scales for Gas-Particle Partitioning Equilibration of Secondary Organic Aerosol Formed from Alpha-Pinene Ozonolysis, Environ. Sci. Technol., 47, 5588-5594, doi:10.1021/es400078d, 2013.

Salo, K., Hallquist, M., Jonsson, A. M., Saathoff, H., Naumann, K.H., Spindler, C., Tillmann, R., Fuchs, H., Bohn, B., Rubach, F., Mentel, Th. F., Müller, L., Reinnig, M., Hoffmann, T., and Donahue, N. M.: Volatility of secondary organic aerosol during $\mathrm{OH}$ radical induced ageing, Atmos. Chem. Phys., 11, 11055-11067, doi:10.5194/acp-11-11055-2011, 2011. 
Saxena, P. and Hildemann, L. M.: Water-soluble organics in atmospheric particles: A critical review of the literature and application of thermodynamics to identify candidate compounds, J. Atmos. Chem., 24, 57-109, 1996.

Seinfeld, J. H. and Pankow, J. F.: Organic atmospheric particulate material, Annu. Rev. Phys. Chem., 54, 121-140, doi:10.1146/annurev.physchem.54.011002.103756, 2003.

Shilling, J. E., Chen, Q., King, S. M., Rosenoern, T., Kroll, J. H., Worsnop, D. R., DeCarlo, P. F., Aiken, A. C., Sueper, D., Jimenez, J. L., and Martin, S. T.: Loading-dependent elemental composition of a-pinene SOA particles, Atmos. Chem. Phys., 9, 771-782, doi:10.5194/acp-9-771-2009, 2009.

Stanier, C. O., Pathak, R. K., and Pandis, S. N.: Measurements of the volatility of aerosols from alpha-piniene ozonolysis, Environ. Sci. Technol., 41, 2756-2763, doi:10.1021/es0519280, 2007.

Tolocka, M. P., Jang, M., Ginter, J. M., Cox, F. J., Kamens, R. M., and Johnston, M. V.: Formation of oligomers in secondary organic aerosol, Environ. Sci. Technol., 38, 1428-1434, doi:10.1021/es035030r, 2004.

Trump, E. R. and Donahue, N. M: Oligomer formation within secondary organic aerosols: equilibrium and dynamic considerations, Atmos. Chem. Phys., 14, 3691-3701, doi:10.5194/acp-143691-2014, 2014.

Vaden, T. D., Imre, D., Beránek, J., Shrivastava, M., and Zelenyuk, A.: Evaporation kinetics and phase of laboratory and ambient secondary organic aerosol, Proc. Natl. Aca. Sci. USA, 108, 2190-2195, doi:10.1073/pnas.1013391108, 2011.

Virtanen, A., Joutsensaari, J., Koop, T., Kannosto, J., Yli-Pirila, P., Leskinen, J., Makela, J. M., Holopainen, J. K., Poschl, U., Kulmala, M., Worsnop, D. R., and Laaksonen, A.: An amorphous solid state of biogenic secondary organic aerosol particles, Nature, 467, 824-827, doi:10.1038/nature09455, 2010.
Weber, R. J., Sullivan, A. P., Peltier, R. E., Russell, A., Yan, B., Zheng, M., de Gouw, J., Warneke, C., Brock, C., Holloway, J. S., Atlas, E. L., and Edgerton, E.: A study of secondary organic aerosol formation in the anthropogenic-influenced southeastern United States, J. Geophys. Res.-Atmos., 112, D13302, doi:10.1029/2007jd008408, 2007.

Wilson, J., Imre, D., Beranek, J., Shrivastava, M., and Zelenyuk, A.: Evaporation Kinetics of Laboratory-Generated Secondary Organic Aerosols at Elevated Relative Humidity, Environ. Sci. Technol., 49, 243-249, 2015.

Yasmeen, F., Vermeylen, R., Szmigielski, R., Iinuma, Y., Böge, O., Herrmann, H., Maenhaut, W., and Claeys, M.: Terpenylic acid and related compounds: precursors for dimers in secondary organic aerosol from the ozonolysis of $\alpha$ - and $\beta$-pinene, Atmos. Chem. Phys., 10, 9383-9392, doi:10.5194/acp-10-9383-2010, 2010.

Zaveri, R. A., Easter, R. C., Shilling, J. E., and Seinfeld, J. H.: Modeling kinetic partitioning of secondary organic aerosol and size distribution dynamics: representing effects of volatility, phase state, and particle-phase reaction, Atmos. Chem. Phys., 14, 5153-5181, doi:10.5194/acp-14-5153-2014, 2014.

Zhang, Q., Worsnop, D. R., Canagaratna, M. R., and Jimenez, J. L.: Hydrocarbon-like and oxygenated organic aerosols in Pittsburgh: insights into sources and processes of organic aerosols, Atmos. Chem. Phys., 5, 3289-3311, doi:10.5194/acp-5-32892005, 2005.

Zhang, X., Cappa, C. D., Jathar, S. H., McVay, R. C., Ensberg, J. J., Kleeman, M. J., and Seinfeld, J. H.: Influence of vapor wall loss in laboratory chambers on yields of secondary organic aerosol, Proc. Natl. Aca. Sci. USA, 111, 5802-5807, doi:10.1073/pnas.1404727111, 2014. 